\title{
Structure of a Swirl-Stabilized, Combusting Spray
}

Daniel L. Bulzan

Lewis Research Center

Cleveland, Ohio

August 1994

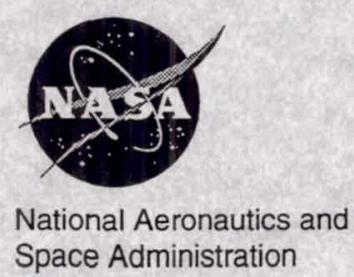




\author{
Structure of a Swirl- \\ Stabilized, Combusting Spray \\ Daniel L. Bulzan \\ NASA Lewis Research Center \\ Cleveland, Ohio 44135
}

\begin{abstract}
Measurements of the structure of a swirl-stabilized, reacting spray are presented. The configuration consisted of a research air-assist atomizer located in the center surrounded by a coflowing air stream. Both the air assist and coflow streams had swirl imparted to them in the same direction with $\mathbf{4 5}$ degree angle swirlers. The fuel and air entered the combustor at ambient temperature and the combustor was operated in an unconfined environment. The gas phase was seeded with aluminum oxide particles in order to obtain velocity measurements. Velocity measurements for the gas phase are reported for both an isothermal, single-phase case without drops and a reacting spray case at axial distances from 2.5 to $350 \mathrm{~mm}$ downstream of the nozzle. Both mean and fluctuating values are reported. Heptane fuel was used for all the experiements. Drop size and velocity, and drop number flux are also reported for five axial distances downstream. Both mean and fluctuating values are reported for the drops. The measurements were performed using a two-component phase/Doppler particle analyzer. Profiles across the entire flowfield where velocities were significant are presented. Mean gas phase temperatures were also measured intrusively using a single pt/pt-13\% thermocouple and are reported at axial distances from 2.5 to $200 \mathrm{~mm}$ downstream of the nozzle.
\end{abstract}

\title{
INTRODUCTION
}

Combusting sprays are very important for a large number of propulsion applications. Important physical processes involved in combusting sprays are the interactions between the droplets and the gas phase, the vaporization of the droplets, and chemical reaction with associated heat release. These physical processes are all coupled and can only be completely described using numerical modeling. As part of an effort to improve the numerical modeling of spray combustion for gas turbine combustors, an experimental study has been performed to obtain a data set for a liquid-fueled combustor with simplified geometry that can be used for comparison with numerical models.

Because of their numerous practical applications, swirling flows with combustion have been studied by a large number of investigators. Earlier reviews of swirling flows both with and without combustion are presented by Chigier', Syred and Beer ${ }^{2}$, and Lilly ${ }^{3}$. These papers predate the development of non-intrusive, laser-based diagnostics; consequently all of the results described were obtained using instrusive instrumentation and detailed structure measurements for these types of flows were not possible.

With the advent of newer instrumentation techniques, namely laser Doppler anemometry (LDA), velocity measurements could be obtained and additional details of the structure of these types of flows began to emerge. Laser Doppler anemometry velocity measurements in spray flames are reported by Styles and Chigier ${ }^{4}$ and Khalil and Whitelaws. They reveal some of the flowfield structure of swirling flames but drop size and size correlated velocity measurements were not possible.

The development of the phase/Doppler particle analyzer, reported by Bachalo and Housers, enabled the simultaneous measurement of droplet size and velocity. This instrument has been used by a number of investigators for measurements in spray flames in a variety of configurations. Mao, et al. ${ }^{7}$ present phase/Doppler measurements of Sauter Mean Diameter (SMD), mean axial drop velocity, drop number density and liquid flux in a swirl-stabilized unconfined spray flame using an air-assist atomizer. No gas phase results are reported and the measurements were taken from 10 to $75 \mathrm{~mm}$ downstream of the nozzle. McDonell and Samuelsen ${ }^{8}$ present measurements taken using a two-component phase/Doppler system in a model can combustor under reacting and non-reacting conditions. The measurements were reported from 50 to $100 \mathrm{~mm}$ downstream of the nozzle. Edwards, et al.' report drop size, drop velocity, drop size distribution, and liquid volume flux in a swirl-stabilized, semi-confined flame at 10 to $100 \mathrm{~mm}$ 
downstream of the nozzle. Gas phase velocities are reported at axial locations from 25 to $100 \mathrm{~mm}$ downstream using a combination of standard LDA with gas-phase seeding and phase/Doppler measurements for 2 micron drops where possible. No gas phase results are reported at $10 \mathrm{~mm}$ downstream. Edwards and Rudoff ${ }^{10}$ report mean drop and gasphase velocity vectors for the same configuration. The gas phase measurements were obtained using a standard LDA system with seeding particles and were reported to be "biased" in regions where a substantial number of drops were present. Ghaffarpour and Chehroudi ${ }^{11}$ present phase/Doppler measurements in a swirl-stabilized, confined combustor at axial locations from 15 to $100 \mathrm{~mm}$ downstream of the nozzle. Mean drop velocities and SMD are reported at six axial locations. Gas phase velocity was measured using LDA without drops or combustion. Phase/Doppler measurements of drop size and velocity as well as gas-phase velocity in a swirl-stabilized combusting spray are reported by McDonell and Samuelsen ${ }^{12}$. The combustion air flow was seeded in order to make the gas phase measurements. Measurements are reported at axial distances of 50,75 , and $100 \mathrm{~mm}$ downstream of the nozzle. Hassa, et al. ${ }^{13}$ presents phase/Doppler measurements in a cylindrical combustor using an air-assist atomizer at axial distances from 7 to $97 \mathrm{~mm}$ downstream of the nozzle. Both drop and gas phase velocities are reported. Gas phase measurements in the reacting flowfield were made using the smaller drops as tracing particles. This required some judgement in order to determine what size drops should be used to represent the gas phase and also required the use of larger drops to represent the gas phase at larger axial distances due to an absence of smaller drops. Temperature measurements were also provided.

Measurements of drop size are also available using other techniques. Presser, et al. ${ }^{14}$ reported drop SMD measurements in a swirl-stabilized confined flame from 10 to $76 \mathrm{~mm}$ downstream of the nozzle using an ensemble light scattering technique. Mean drop velocity measurements were obtained using standard LDA. Gas phase measurements are reported only for the combustion air under isothermal conditions without the presence of the drops. A comparison of drop sizes measured using three techniques is reported by Zurlo, et al. ${ }^{15}$. Measurements were obtained using the ensemble scattering/polarization ratio, phase/Doppler and light intensity deconvolution techniques. Drop mean size and number density measurements were not the same due to the selective sensitivity of each technique to a different size range.

These measurements in swirl-stabilized spray flames have been very useful in providing detailed information regarding the structure of these flowfields. Some of the data from them are also useful for the development of computer models. Most, however, do not provide enough detailed information for both the liquid and gas-phases for the development of models, especially for initial conditions close to the nozzle. Hassa et al. ${ }^{15}$ provides the nearest measurements at $7 \mathrm{~mm}$ from the nozzle.

Apparatus

\section{EXPERIMENT}

The present study is an attempt to provide a set of measurements that can be used in order to gain a better understanding of the physics for combustor type flowfields. The combustor utilized in the present experiment is illustrated in figure 1. It consists of a center mounted air-assist fuel nozzle, Parker Hannifin research simplex airassist atomizer, surrounded by a coflowing air stream. The nozzle orifice diameter was $4.8 \mathrm{~mm}$. Both the air assist and the coflow air streams had swirl imparted to them using 45 degree swirlers. The swirlers were constructed by machining 45 degree slots into rings. Both streams were swirled in the same direction for the present study. The combustion air was not preheated and entered the combustor at $297 \pm 3 \mathrm{~K}$. The top of the air-assist nozzle was water cooled to prevent overheating of an o-ring in the nozzle assembly and keep the atomizing air and liquid fuel at a constant inlet temperature of $297 \pm 3 \mathrm{~K}$. The temperatures of the fuel, atomizing air and coflow air streams were measured using Chromal Alumel thermocouples. Flow rates of the air streams were measured using calibrated orifices and the fuel flow rate was measured using a mass flowmeter. A single set of operating conditions was chosen where the combustor operated in a stable mode, soot was relatively minor, and measurements could be taken near the injector itself. All results reported in the present study were taken at a coflow air flow rate of $13.88 \mathrm{~g} / \mathrm{s}$, an air-assist flow rate of $0.96 \mathrm{~g} / \mathrm{s}$, and a fuel flow rate of $0.38 \mathrm{~g} / \mathrm{s}$. Uncertainty in these flow rates is estimated at \pm 5 percent. The fuel used was heptane. The coflow stream entered the combustor in three radial locations, passed through a honeycomb flow straightener, and then the swirler before exiting the combustor. The swirler was located $140 \mathrm{~mm}$ upstream of the combustor exit in order to minimize wakes from the swirler. The flow from the combustor discharged upwards into ambient, stagnant surroundings. A photograph of the combustor in operation is shown in fig. 2. A laser light sheet with a thickness of approximately $1 \mathrm{~mm}$ was passed through the center of the flowfield 
and used to illuminate the droplet stream. The photograph was taken at 90 degrees relative to the laser light sheet. It is evident that a few very large drops are able to penetrate the combustion zone with a relatively straight trajectory.

The combustor was mounted vertically within a large ( $1.8 \mathrm{~m}$ square by $2.4 \mathrm{~m}$ high) enclosure. The entire enclosure was mounted on two sets of linear bearings and was traversed using stepper motors to provide motion in two directions. The combustor assembly itself could be traversed in the vertical direction using a third stepper motor to allow measurements at all locations in the flowfield. This arrangement allowed rigid mounting of all optical components.

\section{Instrumentation}

A phase/Doppler particle analyzer was used for all velocity and size measurements. A two-component system using green $(514.5 \mathrm{~nm})$ and blue $(488.0 \mathrm{~nm})$ beams from an argon-ion laser operating at 1.5 watts power output was used for the measurements. The transmitting optics utilized a $500 \mathrm{~mm}$ focal length lens combined with a $300 \mathrm{~mm}$ fl collimating lens to yield a focused beam waist of 131 microns for the green and 124 microns for the blue lines. The receiving optics were located 30 degrees off axis in the forward-scatter direction. Light was collected using a $500 \mathrm{~mm}$ focal-length $\mathrm{f} 5.4$ lens and then focused onto a 100 micron by $1 \mathrm{~mm}$ long slit. Details of the instrument can be found in ref. 6 .

In the present study, velocities of both the liquid and gaseous phases were measured. This was accomplished by seeding the gas phase with nominal 1 micron size aluminum-oxide particles. The coflow, air-assist flow, and the ambient surroundings were all seeded to minimize biasing due to concentration gradients. Phase discrimination is inherent in the instrument with the ability to size each measured particle. At each spatial location, two measurements were taken in order to measure the velocity of each phase. A threshold voltage for the photodetectors at the specified laser power was determined experimentally, below which signals from the aluminumoxide particles were not detected. For the droplet measurements, the photodetector voltage was kept below this threshold value in order to eliminate interference from the aluminum-oxide particles. Particles with diameters smaller than 2.4 microns were used to represent the gas phase velocity. Two complete traverses at each axial station were performed in order to measure all three components of velocity and provide a check on flow symmetry. Each traverse measured axial velocity and either radial or tangential velocity. Generally, 64000 measurement attempts were made at each measurement location. In regions where there were few drops, data was taken for a minimum of $600 \mathrm{~s}$. The percentage of validated measurements varied depending on the number density, size distribution, and velocities of drops at each location, but generally ranged from about 65 to 90 percent for the drop measurements. Validation with particle sizing for the gas phase measurements using the aluminum-oxide seeding particles was much lower and generally averaged about 20 percent. Where drops were not present in the flowfield, the gas phase measurements of velocity were taken with sizing disabled. Tests at these locations showed essentially no difference in measured values with the sizing disabled compared to measurements taken with the sizing enabled.

Gas phase mean temperatures were measured using a single pt/pt-13\%rh thermocouple traversed through the flowfield. The $16 \mathrm{~cm}$ long thermocouple had a metal sheath $1.59 \mathrm{~mm}$ in diameter for rigidity. It was insulated with high-temperature alumina and had an exposed junction with a bead diameter of $0.5 \mathrm{~mm}$. Thermocouple voltages were sampled at a rate of $1250 \mathrm{~Hz}$ using a 12 bit analog to digital signal conversion board. The reference temperature was taken at the terminal strip where voltages were measured and updated with each measurement. Each temperature measurement reported represents a time-averaged reading for 5 seconds. No attempt was made to shield the junction from drop impingement since the flowfield was noticeably disturbed when the thermocouple was introduced directly into the spray region. This is reflected in the results where immersion in the spray produced very low temperatures. At locations outside of the spray region, the presence of the thermocouple did not have a noticable effect on the flame.

\section{UNCERTAINTY ANALYSIS}

Uncertainty in position measurements is estimated to be $\pm 0.2 \mathrm{~mm}$ for both radial and axial measurements. Uncertainty in velocity and temperature measurements was estimated by measurement repetition at a number of points in the flowfield. Drop size uncertainty in an isothermal momodisperse drop stream is estimated at \pm 6.5 percent based on calibration and probably is larger in an evaporating spray containing a size distribution. For drop velocities, uncertainty is estimated at \pm 10 percent for mean values and \pm 6 percent for fluctuating values. Since the gas phase measurements require sizing of a very small particle where drops are present, the uncertainty is larger than 
the drop velocity and is estimated at \pm 18 percent for mean velocities and \pm 12 percent for fluctuating velocities. Uncertainty in gas-phase shear stress values are larger and are estimated at \pm 40 percent. Uncertainty in gas phase mean velocity where mean velocities are very small and turbulence is present are larger and are estimated to be \pm 50 percent. These conditions are found near the centerline for radial and tangential velocities and in the entrainment region at the outer edge of the flowfield for all three velocity components. Uncertainties in uncorrected temperature measurements are estimated to be \pm 10 percent. Drop number flux measurement is the most difficult measurement to make because it requires a accurate measurement of drop size, velocity, and probe volume size. This is complicated by the fact that the laser beam power distribution is gaussian and probe volume size is a function of drop size. In addition, in dense regions of the spray, more than one drop can be present in the probe volume at one time causing rejection of the signal which leads to underestimation of the volume flux of the liquid phase. In the present set of measurements, integrating the liquid flux measurements across the flowfield gave $21.3 \%$ of the metered flowrate at $2.5,21.6 \%$ at $5,38.2 \%$ at $10,18.4 \%$ at 20 , and $2.1 \%$ at $50 \mathrm{~mm}$ downstream of the nozzle. Since the largest volume flux should be measured at $2.5 \mathrm{~mm}$ downstream, the measurements reported for drop number flux at 2.5 and $5 \mathrm{~mm}$ downstream are certainly lower than they should be due to the high number densities at these axial locations.

\section{Gas Phase}

\section{RESULTS AND DISCUSSION}

Results are presented for axial locations of $2.5,5,10,20,50,100,200$ and $350 \mathrm{~mm}$ downstream of the nozzle. Gas phase mean axial velocities are presented in figure 3 for isothermal, single-phase flow without drops and two-phase flow with combustion at these eight axial locations downstream of the nozzle. The symmetry of the flowfield is readily apparent. The two 45 degree angle swirlers induce a central recirculation zone along the axis of the flowfield. At $2.5 \mathrm{~mm}$ downstream, the reacting two-phase flow and the isothermal single-phase flow show similar results for mean axial velocity. At this axial location, the maximum mean axial velocity for the reacting case is slightly larger and its radial location is shifted slightly outward compared to the isothermal case. The recirculation zone extends upstream of the first measurement station. This is illustrated by the data at $2.5 \mathrm{~mm}$ downstream, where there is a small region in the center where negative velocities are present. Centerline measurements were attempted at locations closer to the nozzle and indicated that the negative velocities at the centerline persist until approximately $1 \mathrm{~mm}$ from the nozzle. The two peaks in axial velocity are due to the assist-air stream issuing from the center orifice of the nozzle and the coflow stream. The very low axial velocities at radii between 10 and $20 \mathrm{~mm}$ are caused by the top of the nozzle between the central orifice and the coflow air stream. At $5 \mathrm{~mm}$ downstream there are larger differences in axial velocity between the reacting and single-phase cases. The maximum axial velocity and radial location of the peak velocity have increased for the reacting case due to gas expansion caused by the heat release. Beyond a radius of about $15 \mathrm{~mm}$, no differences are apparent between the reacting and single-phase cases. The negative velocities in the recirculation zone have increased for the reacting case and decreased for the single-phase case compared to the results obtained at $2.5 \mathrm{~mm}$ downstream. Similar trends are illustrated at 10 and $20 \mathrm{~mm}$ downstream of the nozzle. At $20 \mathrm{~mm}$ downstream, the maximum axial velocity in the flowfield originating from the coflow stream is larger than that from the air-assist stream for the single-phase case. This is reversed for the reacting case. At $50 \mathrm{~mm}$ downstream, the air-assist and coflow streams have merged and only one axial velocity peak is evident. For the reacting case, the maximum velocity increases, and the radial location of the maximum velocity decreases compared to the single-phase case. Similar results are found at distances of 100, 200 and 350 $\mathrm{mm}$ downstream of the nozzle. At $200 \mathrm{~mm}$ downstream the reacting case has a positive axial velocity at the center indicating the recirculation zone has closed but effects of the recirculation zone still cause a decrease in axial velocity near the center. The single-phase case still has a slight negative axial centerline velocity at this axial location. At $350 \mathrm{~mm}$ downstream, little depression of the axial velocity at the centerline is found for the reacting case. At 350 $\mathrm{mm}$ downstream, traversing limitations prevented measurements from being taken at large radial distances where the axial velocity decays to nearly zero.

Mean radial velocities for the gas phase are presented in figure 4 for eight axial locations downstream of the nozzle. Even at the initial measurement location of $2.5 \mathrm{~mm}$ downstream, large differences are apparent in radial velocity between the reacting and single-phase cases. Maximum radial velocity has increased to about $45 \mathrm{~m} / \mathrm{s}$ for the reacting case compared to $15 \mathrm{~m} / \mathrm{s}$ for the single-phase case due to heat release and expansion of the gas. The increased recirculation zone strength for the reacting case causes the gas to expand more rapidly in the radial 
direction than the axial direction. The radial location for the maximum velocity has also increased for the reacting case compared to the single-phase case. Mean radial velocities at radii larger than about $15 \mathrm{~mm}$ are essentially identical for the single-phase and reacting cases at $2.5 \mathrm{~mm}$ downstream. At 5, 10, and $20 \mathrm{~mm}$ downstream, peak mean radial velocities and radial locations for the peak velocity are considerably increased for the reacting case compared to the single-phase case. Negative radial velocities in the recirculation zone are also increased for the reacting case compared to the single-phase case. At axial distances of $50 \mathrm{~mm}$ and greater, peak positive radial velocities are similar for the two cases. At $100 \mathrm{~mm}$ downstream, a bimodal distribution of positive and negative radial velocities was observed at locations near the center, indicating some unsteadiness in the flowfield. The abrupt shift from negative to positive mean radial velocity in the data at the centerline is caused by a change in the direction of frequency shift at the centerline. This unsteadiness is also evident in large fluctuating radial velocities measured near the center at these axial locations. Some scatter in the data is also evident at $200 \mathrm{~mm}$ downstream.

Mean tangential velocities for the gas phase are presented in fig. 5 for the same axial locations downstream of the nozzle. At axial distances of 2.5 to $10 \mathrm{~mm}$ downstream, peak tangential velocities from the air-assist stream are reduced for the reacting case compared to the single-phase case. Due to the expansion of the gas and the presence of the drops, a decrease is observed in the mean gas-phase angular velocity for the reacting case compared to the single-phase case. Similar to the results shown for the axial and radial velocities, the radial location for the peak mean tangential velocity is also shifted outward for the reacting case. No differences are apparent between the reacting and single-phase cases for the outer mean tangential velocity peak from the coflow stream at axial distances of $10 \mathrm{~mm}$ and less. At axial distances of $20 \mathrm{~mm}$ and larger, the situation is reversed and the reacting case has larger mean tangential velocities compared to the single-phase case. Two distinct peaks are evident at axial distances of $20 \mathrm{~mm}$ and less. The peak nearest the center is due to the swirler in the air-assist stream and the outer peak is caused by the swirler in the coflow air stream. At axial distances of $50 \mathrm{~mm}$ and larger, the air-assist and coflow streams have merged to give a single tangential velocity peak, similar to the results shown for axial velocity.

Fluctuating axial velocities for the gas phase are illustrated in fig. 6 . The fluctuating velocities presented are root-mean-squared values (ms). At $2.5 \mathrm{~mm}$ downstream, little difference in fluctuating axial velocity is evident between the reacting and single-phase cases indicating that the drops have little effect on the fluctuating axial velocity at this location. The maximum fluctuating axial velocity is shifted slightly outward for the reacting case similar to the results previously shown for mean axial velocity. At 5 and $10 \mathrm{~mm}$ downstream, the peak fluctuating axial velocities for the reacting and single-phase cases are again similar, and the location of the peak has also shifted slightly outward for the reacting case. At axial locations of $20 \mathrm{~mm}$ and farther downstream, the reacting case consistently shows higher values of fluctuating axial velocity, however, mean axial velocities were also increased, see fig. 3. At axial locations of $100 \mathrm{~mm}$ and farther downstream, the largest values of fluctuating axial velocity are found at the centerline. At these axial locations fluctuating velocities are not reported at large radii where velocities should decay to nearly zero due to traversing limitations.

Figure 7 presents fluctuating radial velocities for the gas-phase. Again, the values presented are rms values. In contrast to the results for mean radial velocity, peak values of fluctuating radial velocity are quite similar for the reacting and single-phase cases at $2.5 \mathrm{~mm}$ downstream. The radial location of the maximum has shifted radially outward for the reacting case compared to the single-phase case. At $5 \mathrm{~mm}$ and larger distances downstream, maximum values of fluctuating radial velocity for the reacting case are larger than the single-phase case. At axial locations of $50 \mathrm{~mm}$ and farther downstream, peak values of fluctuating radial velocity for the reacting case are found on the centerline and are considerably larger than the single-phase case. This is caused by some unsteadiness in radial velocity near the center, as previously discussed. For the reacting case, fluctuating radial velocities are comparable to fluctuating axial velocities at 2.5 and $5 \mathrm{~mm}$ downstream. At distances of 10 to $50 \mathrm{~mm}$ downstream, fluctuating radial velocities are lower than fluctuating axial velocities for the combusting case. Similar to the previous results for fluctuating axial velocity, at axial distances of $100 \mathrm{~mm}$ downstream and greater, measurements are not reported at radii large enough for measured values to approach zero.

Fluctuating tangential ms velocities for the gas phase are presented in fig. 8 for the single-phase and reacting cases considered in the present study. Similar to the results previously illustrated for the mean tangential velocity, at axial locations less than $20 \mathrm{~mm}$ from the nozzle, fluctuating tangential velocities for the gas phase are reduced for the reacting case compared to the single-phase case. At axial locations of $20 \mathrm{~mm}$ and farther downstream, fluctuating tangential velocities are larger for the reacting case except near the edges of the flowfield. At axial locations of $50 \mathrm{~mm}$ and larger, the peak fluctuating tangential velocity is located at the centerline. 
Fluctuating tangential velocities are less than fluctuating radial velocities at axial locations $20 \mathrm{~mm}$ and closer to the nozzle. At axial distances larger than $20 \mathrm{~mm}$ downstream, fluctuating tangential and radial velocities are similar. At very large downstream distances, $350 \mathrm{~mm}$ downstream, all three components of fluctuating velocity are similar. Measurements of the shear stress $u^{\prime} v^{\prime}$ for the gas phase are presented in figure 9. Results are again presented at the eight axial locations for the reacting and single-phase cases. As discussed in the uncertainty analysis, there is more uncertainty in the shear stress measurements compared to those previously presented. Cubic spline fits to each data point are drawn in order assist in the interpretation of the data at locations up to $20 \mathrm{~mm}$ from the nozzle. At $2.5 \mathrm{~mm}$ downstream, the largest values of $u$ ' $v$ ' are found in the shear region between the air-assist stream and the recirculation zone where large velocity gradients exist. The maximum positive value is shifted radially outward and is slightly higher for the reacting case compared to the single-phase case. This is also very evident at 5,10 and $20 \mathrm{~mm}$ downstream. A negative value of u'v' at a radius of about $10 \mathrm{~mm}$ at $2.5 \mathrm{~mm}$ downstream is evident for the reacting case that is not shown for the single-phase case. The reacting case has a sharp decrease in radial velocity at this radial location as shown in figure 4 . At $50 \mathrm{~mm}$ downstream peak positive values are similar for the single phase and reacting cases but larger negative peaks are observed for the latter case due to the larger negative radial velocities for the reacting case. At larger downstream distances, measured values of u'v' decrease considerably for both the reacting and single-phase cases. The reacting case has slightly larger positive and negative values of 'u'v' than the single-phase case.

Measurements of the shear stress u'w' for the gas phase are presented in figure 10 to complete the set of gas phase measurements. At 2.5 and $5 \mathrm{~mm}$ downstream, the single-phase case has larger positive values of u'w' compared to the reacting case. At these axial locations, mean tangential velocities were also reduced for the reacting case as previously illustrated in fig. 5. Similar to the results for 'u'v', a negative peak of u'w' is evident for the reacting case but not for the single-phase case. At 10 and $20 \mathrm{~mm}$ downstream, the measurements show dramatic differences between the two cases. The single-phase case has positive u'w'peaks while the reacting case is generally negative. For the reacting case, at 10 to $20 \mathrm{~mm}$ downstream, the larger peak in mean tangential velocity shifts to the peak found at a larger radius and the tangential velocities for the reacting case are now larger than those from the single-phase case. At $50 \mathrm{~mm}$ downstream, the shear stress u'w' for the reacting case now has a positive peak, although it is relatively small. At larger downstream distances, u'w' decays considerably and measured values are quite small at $350 \mathrm{~mm}$ downstream for both cases.

\section{Liquid Phase}

Mean axial velocity for the drops is illustrated in fig. 11. Results are presented at downstream locations of $2.5,5,10,20$, and $50 \mathrm{~mm}$ downstream of the nozzle. At the next measurement position of $100 \mathrm{~mm}$, not enough drops were present to have confidence in the velocity measurements. Results are illustrated for drop diameters of $6.9,15.4,23.8,40.8,66.2$, and 97.2 microns. Each drop diameter has a size range of 2.8 microns. Velocity measurements for a particular size are not presented at locations where not enough valid measurements were obtained. This is particularly true for the larger drop sizes. Gas phase measurements for the combusting case are illustrated by a solid line representing a spline fit between the measured data points. At axial locations of 2.5 and $5 \mathrm{~mm}$ downstream, it is evident that the smaller drops follow the gas phase velocity more closely than larger drops. In the recirculation zone, even the 6.9 micron drops lag the gas phase by a considerable amount. This was also observed by Hassa, et al. ${ }^{13}$ At $2.5 \mathrm{~mm}$ downstream, the drops are only found in a narrow region of the flow. A relatively large velocity difference between various drop sizes is also apparent. This is especially evident at $5 \mathrm{~mm}$ downstream, where the peak axial velocity of the 66 micron drops is about $20 \mathrm{~m} / \mathrm{s}$ lower than the velocity of the 6.9 micron drops. In the recirculation zone at $5 \mathrm{~mm}$ downstream, only drops with diameters of 23.8 microns and smaller have negative axial velocities. The larger drops have enough momentum to retain positive values of axial velocity in the recirculation zone at this axial location. At $10 \mathrm{~mm}$ downstream, the axial velocity is changing very rapidly as the air-assist stream containing the drops encounters the negative velocities in the recirculation zone. The result is that the peak mean axial velocity for the $\mathbf{4 0 . 8}$ micron drops is similar to the gas phase. The peak velocities of the 6.9 and 15.4 micron drops are nearly identical as the drop velocities adjust to the rapidly changing gas phase flowfield. At $20 \mathrm{~mm}$ downstream, the radial location of the peak velocities of the drops coincides with the edge of the recirculation zone. The drop velocities continue to adjust to this rapidly changing gas phase. This is illustrated by the more rapid decrease in the velocity of the 6.9 micron drops compared to larger drops. The adjustment in drop velocity is complete by $50 \mathrm{~mm}$ downstream where it is evident that the smallest drops again show the least amount 
of slip with the gas phase. At $50 \mathrm{~mm}$ downstream, the drops have larger velocities than the gas phase and the larger drops generally have higher velocities, except for the 66.2 micron drops. At axial distances of $10 \mathrm{~mm}$ downstream and larger, essentially no drops are found in the central regions of the flowfield. Due to the evaporation of the drops, very few larger drops are found at $50 \mathrm{~mm}$ downstream of the nozzle.

Measurements of mean radial velocity for the drops are presented in fig. 12 for the six drop diameters at the same five axial distances downstream of the nozzle. Again, the gas-phase measurements are indicated by a solid line. Results for mean radial velocity are very similar to those previously observed for axial velocity. At axial distances of 2.5 and $5 \mathrm{~mm}$ downstream, the size-velocity correlation is very ordered with the 6.9 micron drops tracking the gas-phase flowfield more closely than the larger drops. At the outer edge of the flowfield, the gas-phase radial velocity decays quite rapidly resulting in relatively large slip velocities between the drops and the gas phase, even for the 6.9 micron drops. At $5 \mathrm{~mm}$ downstream, only the smaller drops are carried into the recirculation zone, illustrated by their negative radial velocities. At 10 and $20 \mathrm{~mm}$ downstream, as previously discussed for axial velocity, the gas phase mean radial velocity is also changing very rapidly as the air-assist stream is strongly influenced by the central recirculation zone. The momentum of the evaporating drops present at these axial locations cause their velocities to be significantly different than the gas phase. At $50 \mathrm{~mm}$ downstream, the drop velocities have adjusted to the gas phase flowfield and the smaller drops again show the least amount of slip with the gas phase. Similar to the results previously shown for axial velocity, the larger drops have significantly larger velocities than the gas phase at this distance downstream.

Mean tangential velocity measurements for the drops are presented in fig. 13 for the same six drop sizes and axial locations as the previous two figures. It is apparent that the tangential velocities are considerably lower and not as symmetric as previously observed for axial or radial velocities. At all axial locations, the size-velocity correlation is very uniform for mean tangential velocity. The larger drops have lower mean tangential velocities than smaller drops. The gas-phase tangential velocity does not undergo the very rapid changes observed for the radial and axial velocities and the drops are able to adjust to the changes. Again, very few large drops are found at the $50 \mathrm{~mm}$ downstream location due to the evaporation of the drops.

Fluctuating axial velocity measurements for the drops are presented in fig. 14. At axial locations of 2.5 and $5 \mathrm{~mm}$ downstream, the fluctuating axial velocity is correlated with drop size. The smaller drops have larger fluctuating velocities than larger drops and the drop velocity fluctuations are lower than those found in the gas phase. Similar to the results illustrated for mean axial velocity, at downstream distances of 10 and $20 \mathrm{~mm}$, the gas-phase environment that the drops encounter is changing so rapidly that the drop velocity fluctuations lag the development of the flowfield. At $20 \mathrm{~mm}$ downstream, the 6.9 micron drops generally have lower fluctuating axial velocities than the 15.4 and 23.8 micron drops, but higher fluctuating velocities than the 66.2 and the 40.8 micron drops. The drop fluctuating velocities are also lower than the gas phase, except at locations in the central recirculation zone. At 50 $\mathrm{mm}$ downstream, the 6.9 micron drops have fluctuating velocities similar to the gas phase. Similar to the results illustrated for mean axial velocity, the larger drops tend to have larger fluctuating axial velocities at $50 \mathrm{~mm}$ downstream except for the 66.2 micron drops. There are also considerably fewer larger drops at this axial location due to evaporation; consequently, the results are based on fewer validated measurements which would increase the uncertainty in the measurements.

Fig. 15 presents measurements of fluctuating radial velocity for the drops. Results are similar to those previously shown for fluctuating axial velocity. At $2.5,5$ and $10 \mathrm{~mm}$ downstream, the smaller drops tend to have larger fluctuating velocities and all fluctuating drop velocities are smaller than the gas phase. As previously discussed, between 10 and $20 \mathrm{~mm}$ downstream, the gas phase radial velocity changes so rapidly that drop velocity development lags considerably. By the time the drops travel to $50 \mathrm{~mm}$ downstream, the drops generally have larger fluctuating radial velocities than the gas phase, however, they also have larger mean radial velocities, see fig. 12.

Fluctuating tangential velocities for the drops are presented in fig. 16. As previously illustrated for mean tangential velocities, fluctuating tangential drop velocities are correlated with drop size at all axial locations. Fluctuating tangential velocity increases with decreasing drop size and all fluctuating drop velocities are lower than the gas phase. At 10 and $20 \mathrm{~mm}$ downstream, where the gas phase flowfield is changing rapidly, the difference in fluctuating tangential velocity between the drops and the gas phase is larger than at other axial locations. Relatively large differences are apparent, even for the 6.9 micron drops. At an axial distance of $50 \mathrm{~mm}$ downstream, the 6.9 micron drops have fluctuating velocities about equal to the gas phase and fluctuating velocities of larger drops are lower. 
To complete the drop measurements, drop number fluxes for the six drop sizes are presented in fig. 17. The results are provided as the number of drops $/ \mathrm{cm}^{2} \mathrm{~s}$ and are plotted on a $\log$ scale. The instrument divides the drop size distribution into 50 size bins. These 50 bins were combined into 10 sizes in order to make the data set manageable. In this figure, six of the 10 combined drop size bins are presented. The diameters presented represent mean values of size bins with a width of 8.5 microns for the $6.9,15.4,23.8$ and 40.8 micron drops, a width of 14.2 microns for the 66.2 micron drops, and a width of 19.2 microns for the 97.2 micron drops. To adequately account for all the measured drops, the number fluxes for the remaining four sizes would also be required. The nozzle used in the present study produced a very large number of relatively small drops, evident in the results at $2.5 \mathrm{~mm}$ downstream. Number flux increases with decreasing drop size, reaching a maximum at a radius of about $6 \mathrm{~mm}$ at $2.5 \mathrm{~mm}$ downstream. The maximum number fluxes show a variation of four orders of magnitude betweem the large and small drop sizes. Drop number fluxes decrease slightly between $2.5,5$ and $10 \mathrm{~mm}$ downstream. As previously discussed, integrated volume fluxes increased between 2.5 and $10 \mathrm{~mm}$ downstream even though actual number flux values decrease, because the drops are found at larger radii. Between 10 and $20 \mathrm{~mm}$ downstream, number fluxes substantially decrease as does the integrated volume flux. At $50 \mathrm{~mm}$ downstream, most of the drops have evaporated and the remaining drops are smaller. Very few drops are found in the center at $2.5 \mathrm{~mm}$ downstream and by $10 \mathrm{~mm}$ downstream of the nozzle, essentially no drops are found in the central recirculation zone. There is a slight asymmetry evident in the number fluxes at 5 and $50 \mathrm{~mm}$ downstream. The positive values of radius have slightly reduced number fluxes compared to the negative side. Integrated liquid volume fluxes generally were also larger for the negative side.

\section{Temperature}

Gas phase average temperatures are presented in fig. 18. Radial profiles are presented for axial locations from 2.5 to $200 \mathrm{~mm}$ downstream of the nozzle. Results are presented illustrating both the temperature measurements as taken and the measurement corrected for radiation heat loss from the thermocouple. The radiation correction was performed similar to Shuen et al. ${ }^{16}$, considering only radiation heat loss to ambient surroundings and neglecting any radiation heat transfer from the soot present in the flame. The temperature corrections varied with temperature level up to a maximum of about $150 \mathrm{~K}$. At $2.5 \mathrm{~mm}$ downstream, gas-phase temperature is substantially elevated over the inlet temperature and has a maximum corrected temperature of about $1650 \mathrm{~K}$. The dramatic reductions in temperature for $2.5 \mathrm{~mm}$ downstream at a radius of about $5 \mathrm{~mm}$ are caused by droplet impingement on the thermocouple bead; therefore, these measurements are not realistic gas phase temperatures. No attempt was made to shield the thermocouple from the drops because the presence of the even the small thermocouple bead in the spray caused visible distortion in the flowfield. A non-intrusive technique is required for accurate gas phase temperature measurements in regions where substantial numbers of drops are present. At $5 \mathrm{~mm}$ downstream, maximum temperatures have increased to about $1840 \mathrm{~K}$. The sharp reductions in temperature due to droplet impingement are still present and are found at a radius of about $9 \mathrm{~mm}$. At $10 \mathrm{~mm}$ downstream, the maximum corrected temperature is about $1825 \mathrm{~K}$ and the width of the higher temperature region is larger. Drop impingement is still evident at a radius of about $15 \mathrm{~mm}$. At $20 \mathrm{~mm}$ downstream, the drop number density has substantially decreased, see fig. 17, and this is reflected in smaller temperature reductions due to drop impingement at a radius of about $21 \mathrm{~mm}$. Similar trends are evident at axial locations farther downstream. At 100 and $200 \mathrm{~mm}$ downstream, very few drops remained and no drop impingement on the thermocouple bead was apparent. Some asymmetry is evident in the temperature profiles, with the negative radius having a higher temperature than the positive. This side had generally higher measurements of volume flux indicating an increase in fuel-air ratio for the negative side compared to the positive.

\section{CONCLUSIONS}

Gas phase axial velocity is increased for the combusting spray case compared to the single-phase isothermal case due to the gas expansion caused by the heat release. The strength of the recirculation zone is also increased for the reacting case and the overall length of the recirculation zone is shorter compared to the single-phase case. At axial distances up to $20 \mathrm{~mm}$ downstream of the nozzle, gas phase mean radial velocities are substantially increased for the reacting spray compared to the single-phase case. Gas phase tangential velocities are reduced for the reacting spray case compared to the single-phase case due to the presence of the drops and the gas expansion due to heat release. At $2.5 \mathrm{~mm}$ downstream, negative axial velocities were measured for a small region at the center of the flowfield for both the reacting and single-phase cases. 
Mean axial and radial velocities for the drops lag the gas phase velocities at axial distances of 2.5 and 5 $\mathrm{mm}$ downstream. At these axial distances downstream, the slip velocity increases with increasing drop size. At 10 and $20 \mathrm{~mm}$ downstream, the drop axial and radial velocities are adjusting to the rapidly changing gas-phase flowfield and the velocity correlation with drop size is not as uniform as observed at smaller distances downstream. At 50 $\mathrm{mm}$ downstream, mean drop axial and radial velocities are larger than the gas phase.

Mean tangential velocities for the drops lag the gas phase at all axial locations downstream of the nozzle. The size velocity correlation is very apparent with the smaller drops showing the least amount of slip with the gas phase. At $20 \mathrm{~mm}$ downstream, the largest velocity difference between the gas phase and the drops is observed.

Drop number fluxes at $2.5 \mathrm{~mm}$ downstream illustrate the drop size distribution produced by the research air-assist atomizer used in the present study. Number fluxes were directly related to drop size with smaller sizes having larger numbers of drops. Drop number fluxes decreased slightly between 2.5 and $5 \mathrm{~mm}$ downstream and then steadily decreased. At $50 \mathrm{~mm}$ downstream drop number fluxes are considerably reduced as well as the number of larger drops.

Mean gas phase temperatures show elevated temperatures at the first axial measurement location of $2.5 \mathrm{~mm}$ downstream of the nozzle due to a small region with negative axial velocities. Maximum gas phase temperatures were observed at $5 \mathrm{~mm}$ downstream of the nozzle and then decreased as axial distance increased. Drop impingement on the thermocouple bead produced very low temperatures in regions where the number of drops were substantial.

\section{ACKNOWLEDGEMENTS}

The author would like to acknowledge the asistance of Ms. Sylvia Merritt in the processing of the phase/Doppler data and Ms. Viviannette Sánchez in the acquisition and processing of the gas phase temperature data.

\section{REFERENCES}

${ }^{1}$ Chigier, N. A., "Gas Dynamics of Swirling Flow in Combustion Systems," Astronautica Acta, Vol 17, 1972 , pp. 387-395.

${ }^{2}$ Syred, N. and Beer, J., "Combustion in Swirling Flows: A Review," Combustion and Flame, Vol. 23, 1974, pp. 143-201.

${ }^{3}$ Lilley, D. G., "Swirl Flows in Combustion: A Review," AIAA J., Vol. 15, No. 8, 1977, pp. 1063-1078.

"Styles, A. C., and Chigier, N. A., "Combustion of Air Blast Atomized Spray Flames," Sixteenth Symposium (International) on Combustion, The Combustion Institute, 1976, pp. 619-630.

${ }^{5}$ Khalil, E. E., and Whitelaw, J. H., "Aerodynamic and Thermodynamic Characteristics of Kerosene-Spray Flames," Sixteenth Symposium (International) on Combustion, The Combustion Institute, 1976, pp. 569-576.

'Bachalo, W. D., and Houser, M. J., "Phase/Doppler Spray Analyzer for Simultaneous Measurements of Drop Size and Velocity Distributions," Optical Engineering, Vol. 23, No. 5, 1984, pp. 583-590.

${ }^{7}$ Mao, C-P, Wang, G., and Chigier, N., "An Experimental Study of Air-Assist Atomizer Spray Flames," Twenty First Symposium (International) on Combustion, The Combustion Institute, 1986, pp. 665-673.

"McDonell, V. G., and Samuelsen, G. S.," Application of Two-Component Phase Doppler Interferometry to the Measurement of Particle Size, Mass Flux, and Velocities in Two-Phase Flows." Twenty Second Symposium (International) on Combustion, The Combustion Institute, 1988, pp. 1961-1971.

'Edwards, C. F., Rudoff, R. C., and Bachalo, W. D., "Measurement of Correlated Drop Size and Velocity Statistics, Size Distribution, and Volume Flux in a Steady Spray Flame," Fifth International Symposium on the Applications of Laser Techniques to Fluid Mechanics, Lisbon, Portugal, July 1990.

${ }^{10}$ Edwards, C. F., and Rudoff R. C., "Structure of a Swirl-Stabilized Spray Flame by Imaging, Laser Doppler Velocimetry, and Phase Doppler Anemometry," Twenty Third Symposium (International) on Combustion, The Combustion Institute, 1990, pp. 1353-1359.

${ }^{11}$ Ghaffarpour, M. and Chehroudi, B., "Experiments on Spray Combustion in a Gas Turbine Model Combustor," Combust. Sci. and Tech., Vol. 92, 1993, pp 173-200.

${ }^{12}$ McDonell, V. G., and Samuelsen, S., "Gas and Drop Behavior in Reacting and Non-Reacting Air-Blast 
Atomizer Sprays," J. Propulsion, Vol. 7, No. 5, 1991, pp. 684-691.

${ }^{13}$ Hassa, C., Deick, A., and Eickhoff, H., "Investigation of the Two-Phase Flow in a Research Combustor under Reacting and Non-Reacting Conditions," AGARD-CP-536, May, 1993, pp. 41-1 - 41-12.

${ }^{14}$ Presser, C., Gupta, A. K., and Semerjian, H. G., "Aerodynamic Characteristics of Swirling Spray Flames: Pressure-Jet Atomizer," Combustion and Flame, Vol. 92, 1993, pp. 25-44.

${ }^{15}$ Zurlo, J. R., Presser, C., Gupta, A., and Semerjian, H. G., "Determination of Droplet Characteristics in Spray Flames Using Three Different Sizing Techniques," AIAA Paper AIAA 91-2200, June 1991.

${ }^{16}$ Shuen, J.-S., Solomon, A. S. P., and Faeth, G. M., "The Structure of Dilute Combusting Sprays," NASA CP 174838, Jan. 1985. 


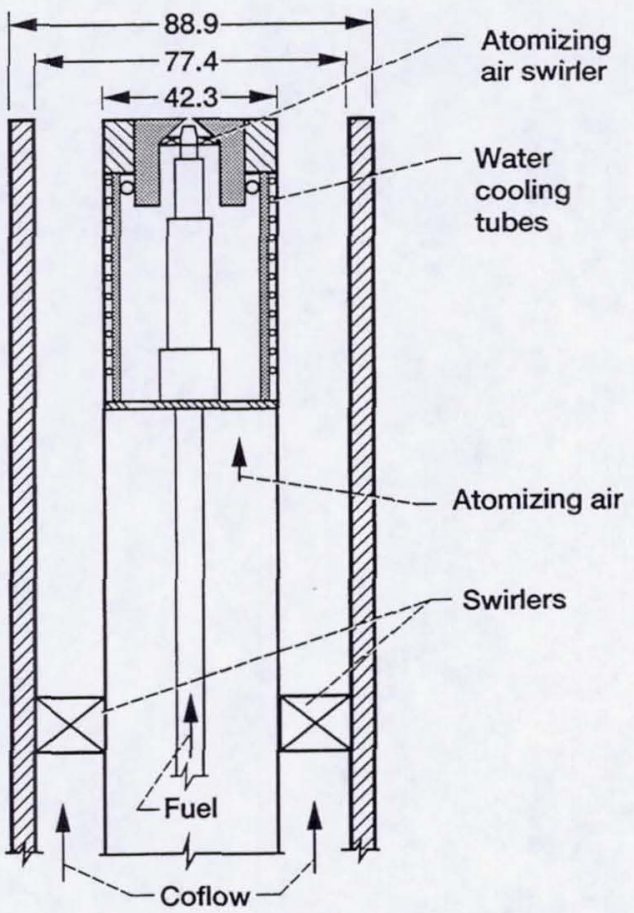

Figure 1.-Schematic drawing of the combustor. Dimensions in $\mathrm{mm}$. 
Page intentionally left blank 


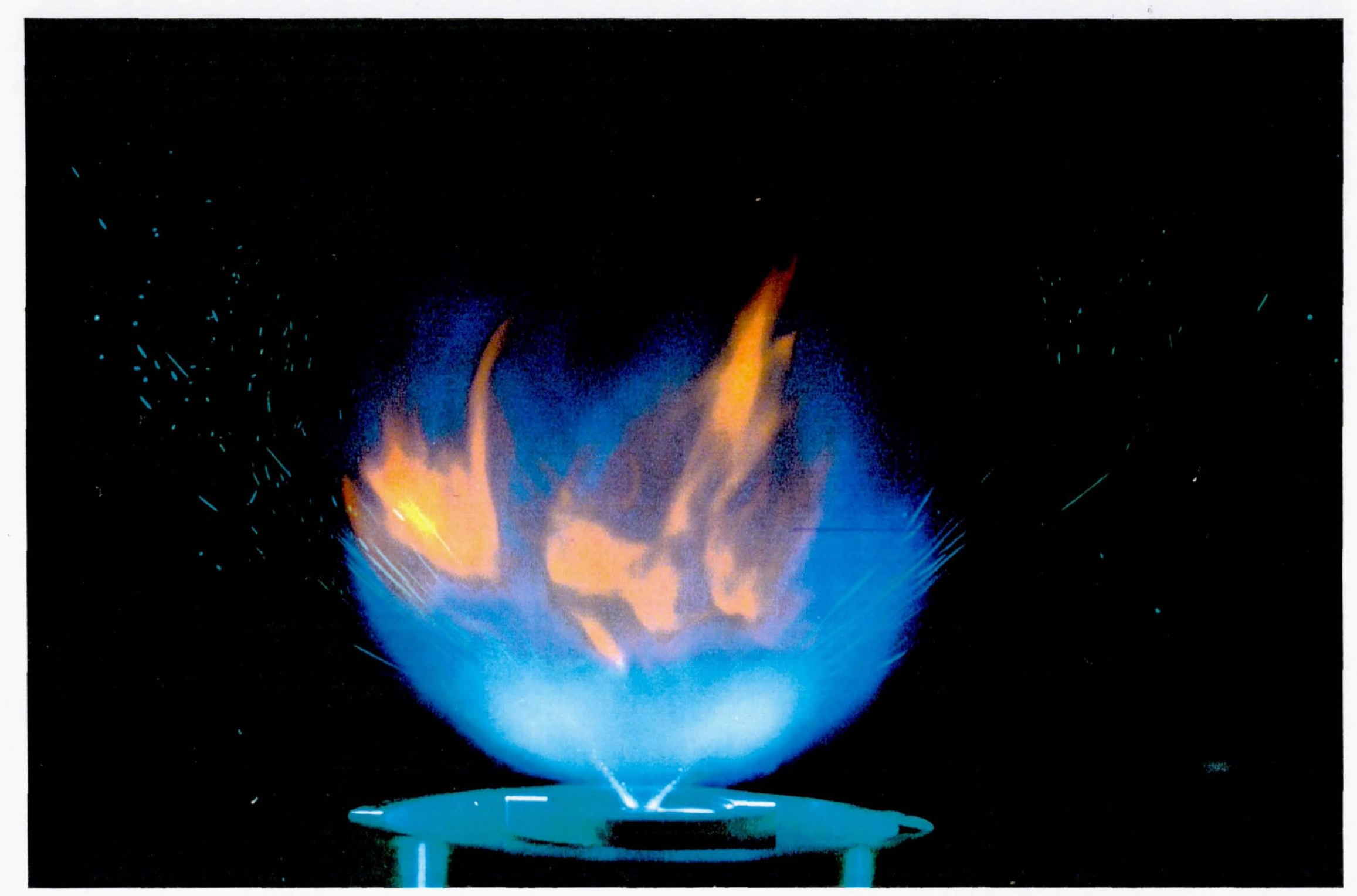

Figure 2.- Photograph of swirl-stabilized, spray flame. 
Page intentionally left blank 

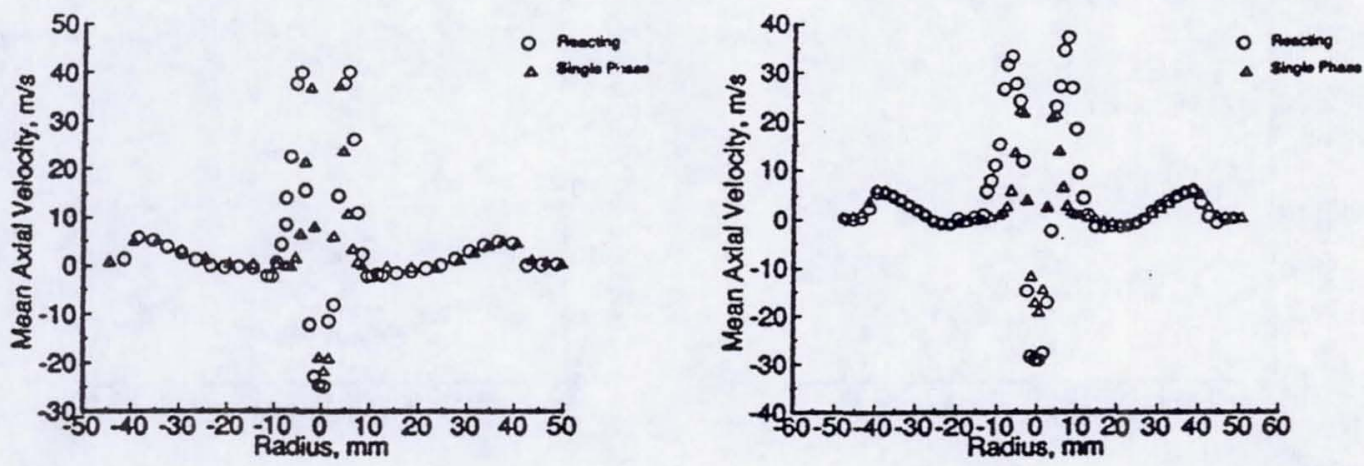

$10 \mathrm{~mm}$ Downstream

20 mm Downstream
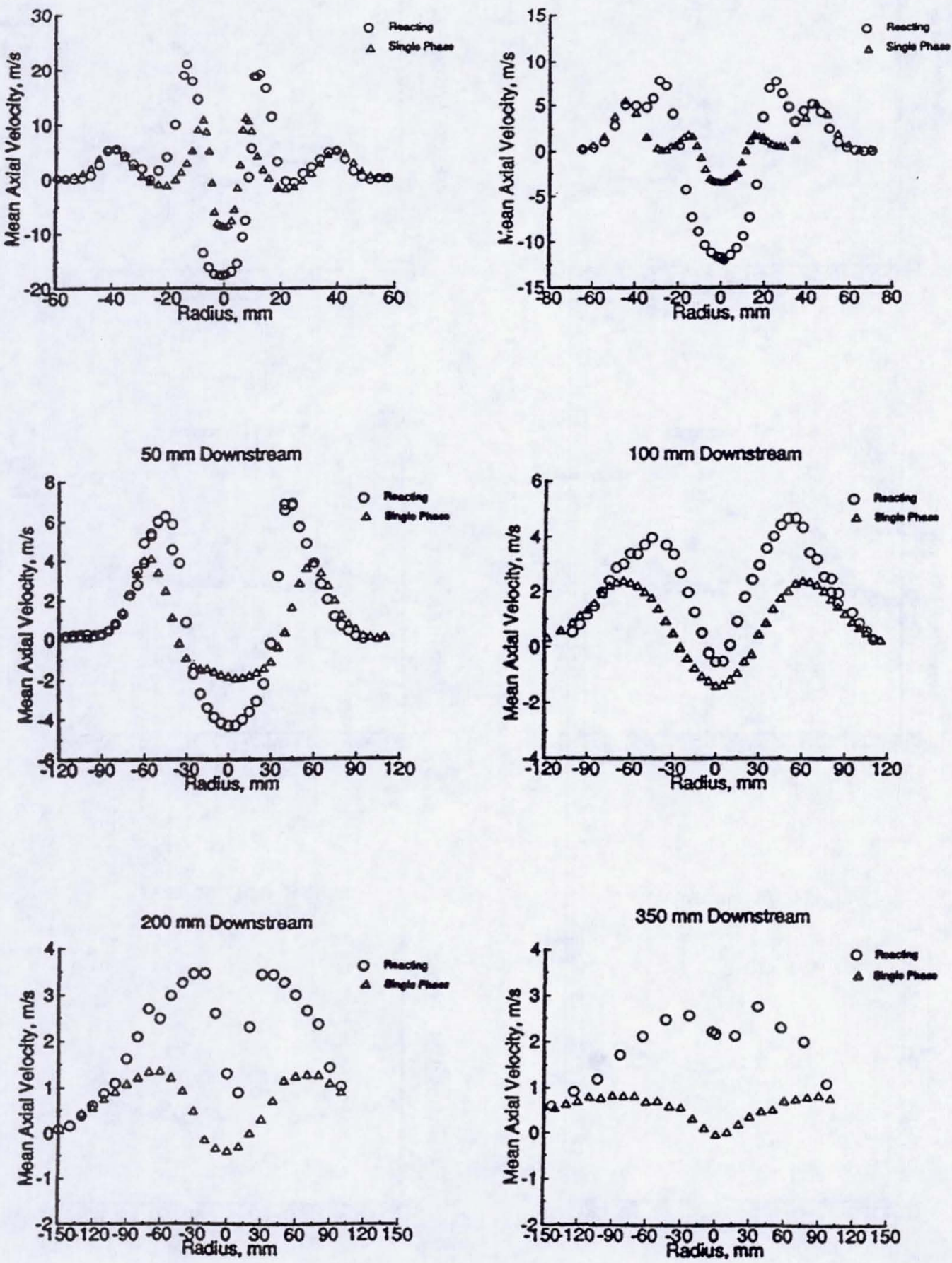

Figure 3.- Gas phase mean axial velocity profiles. 

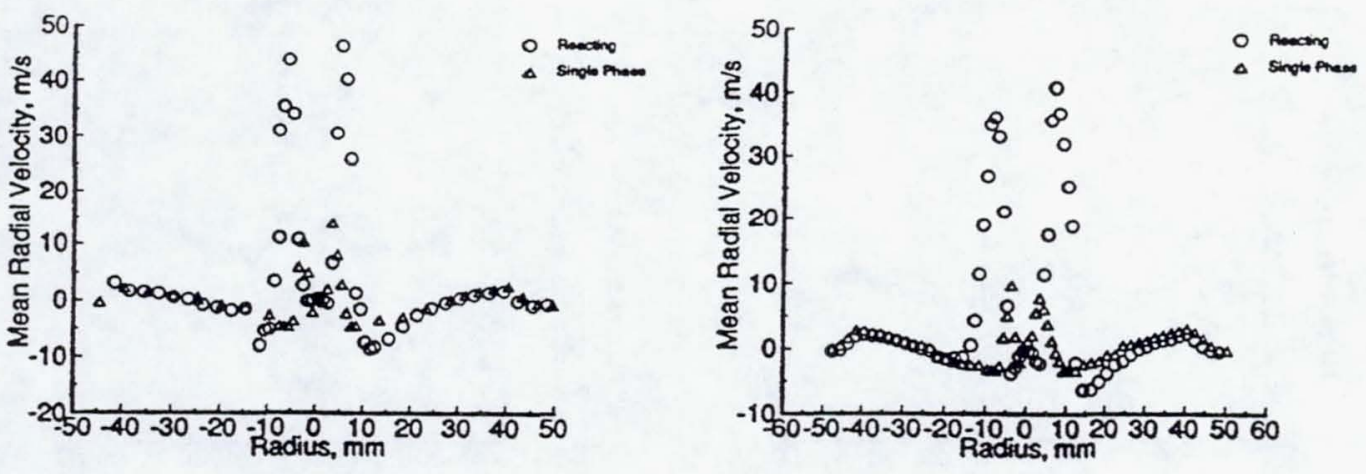

10 mm Downstream
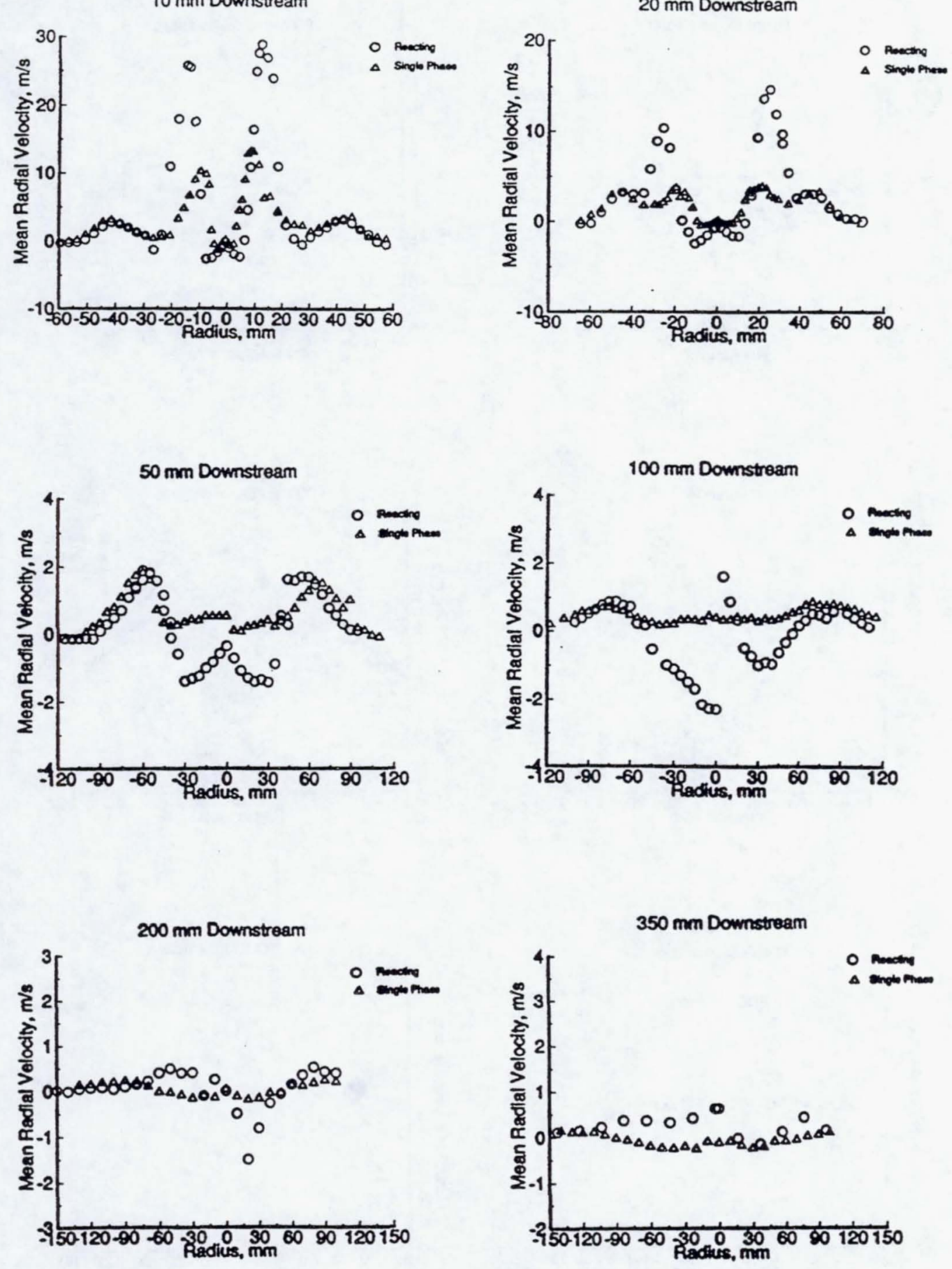

Figure 4.- Gas phase mean radial velocity profiles. 

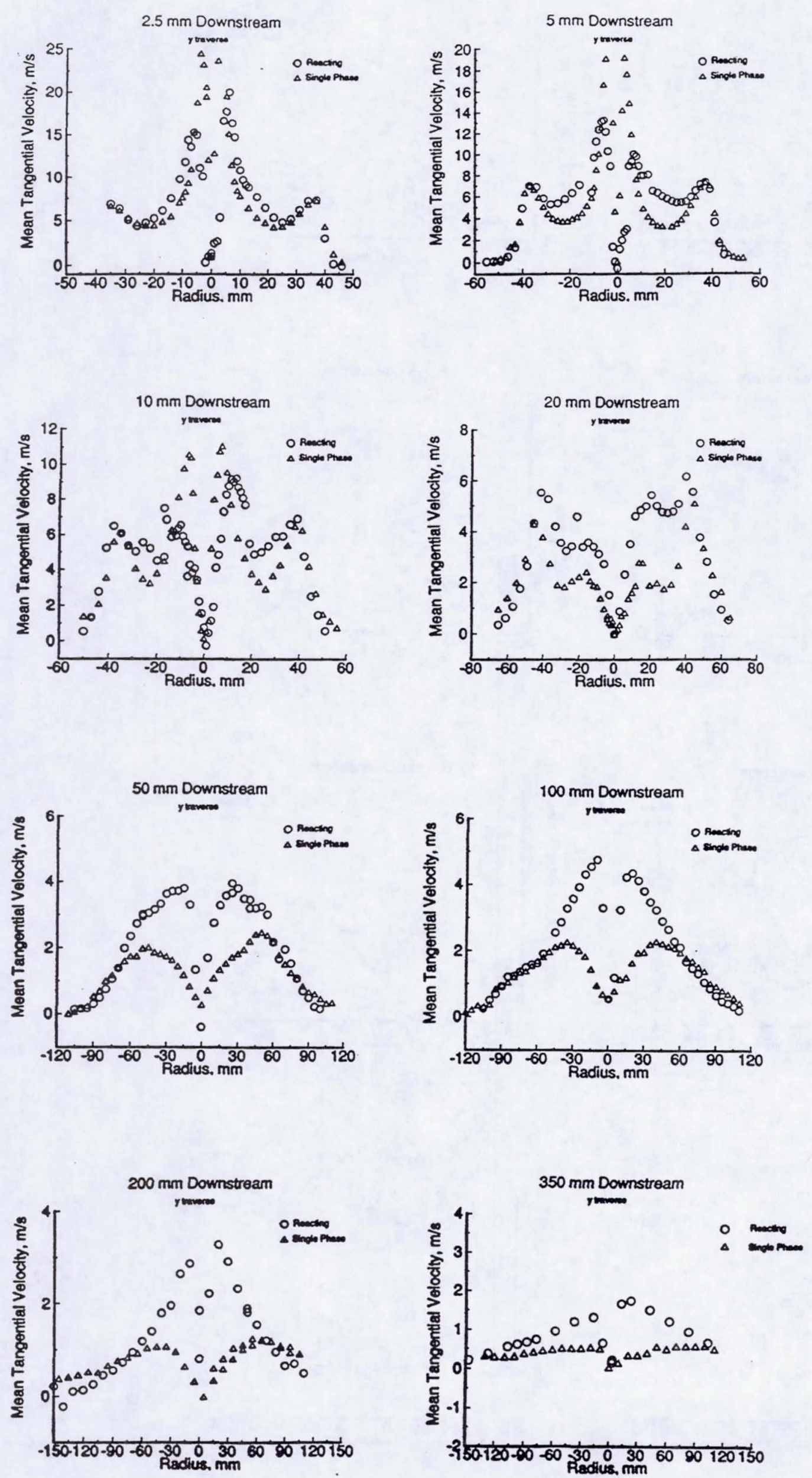

Figure 5.- Gas phase mean tangential velocity profiles. 

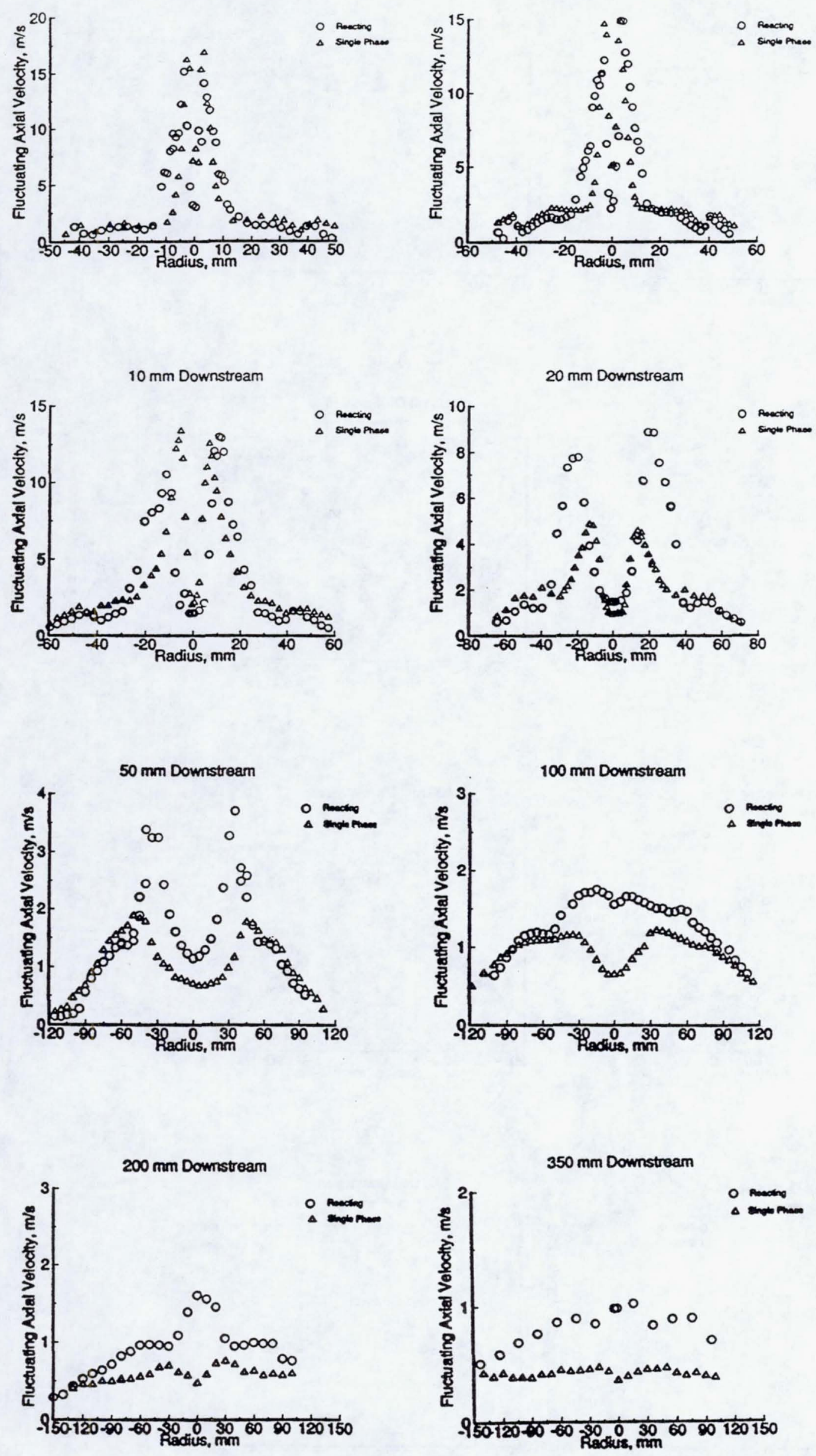

Figure 6.- Gas phase fluctuating axial velocity profiles. 

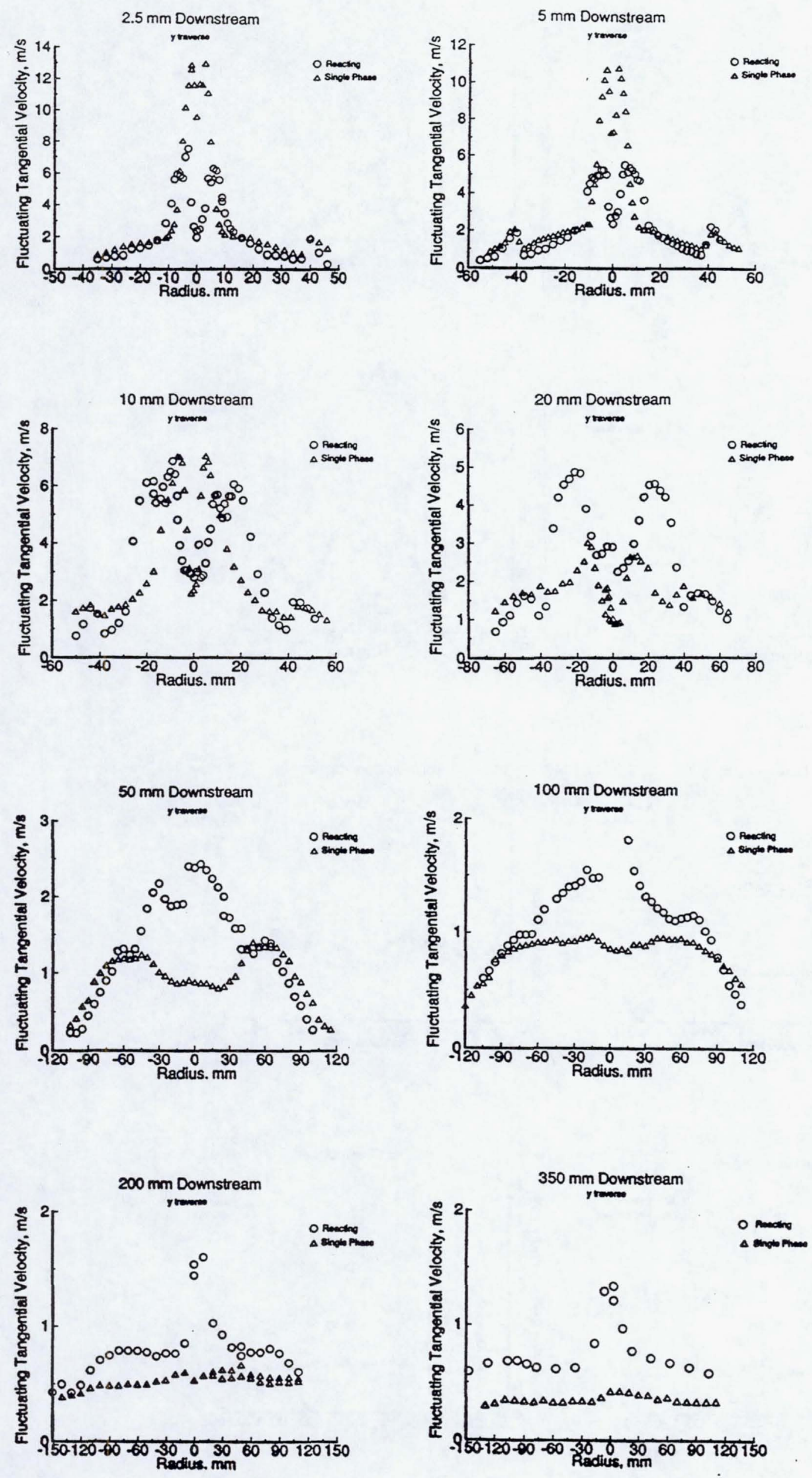

Figure 8.- Gas phase fluctuating tangential velocity profiles. 

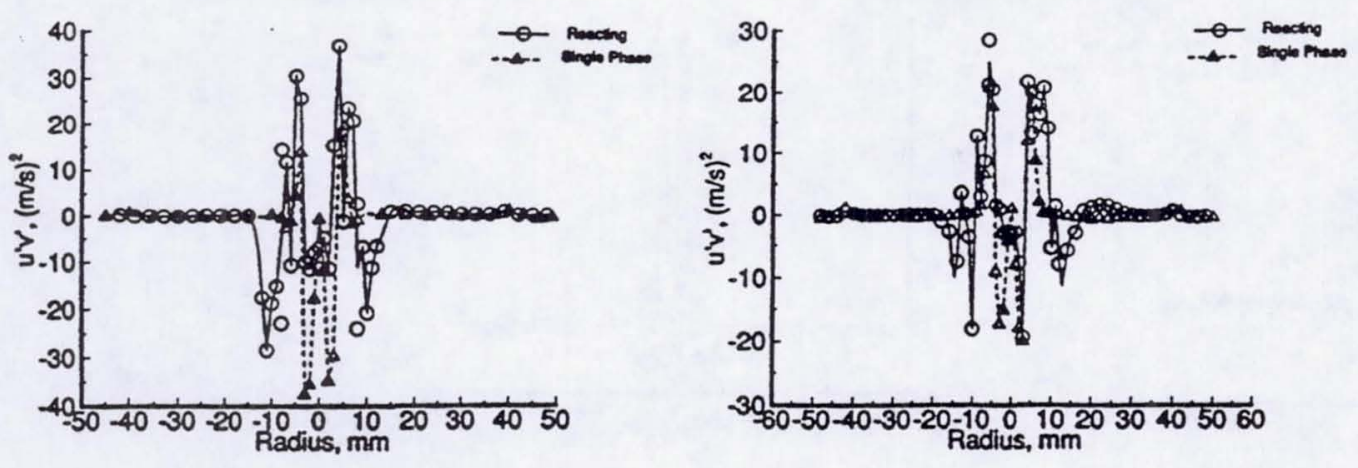

10 mm Downstream

$20 \mathrm{~mm}$ Downstream
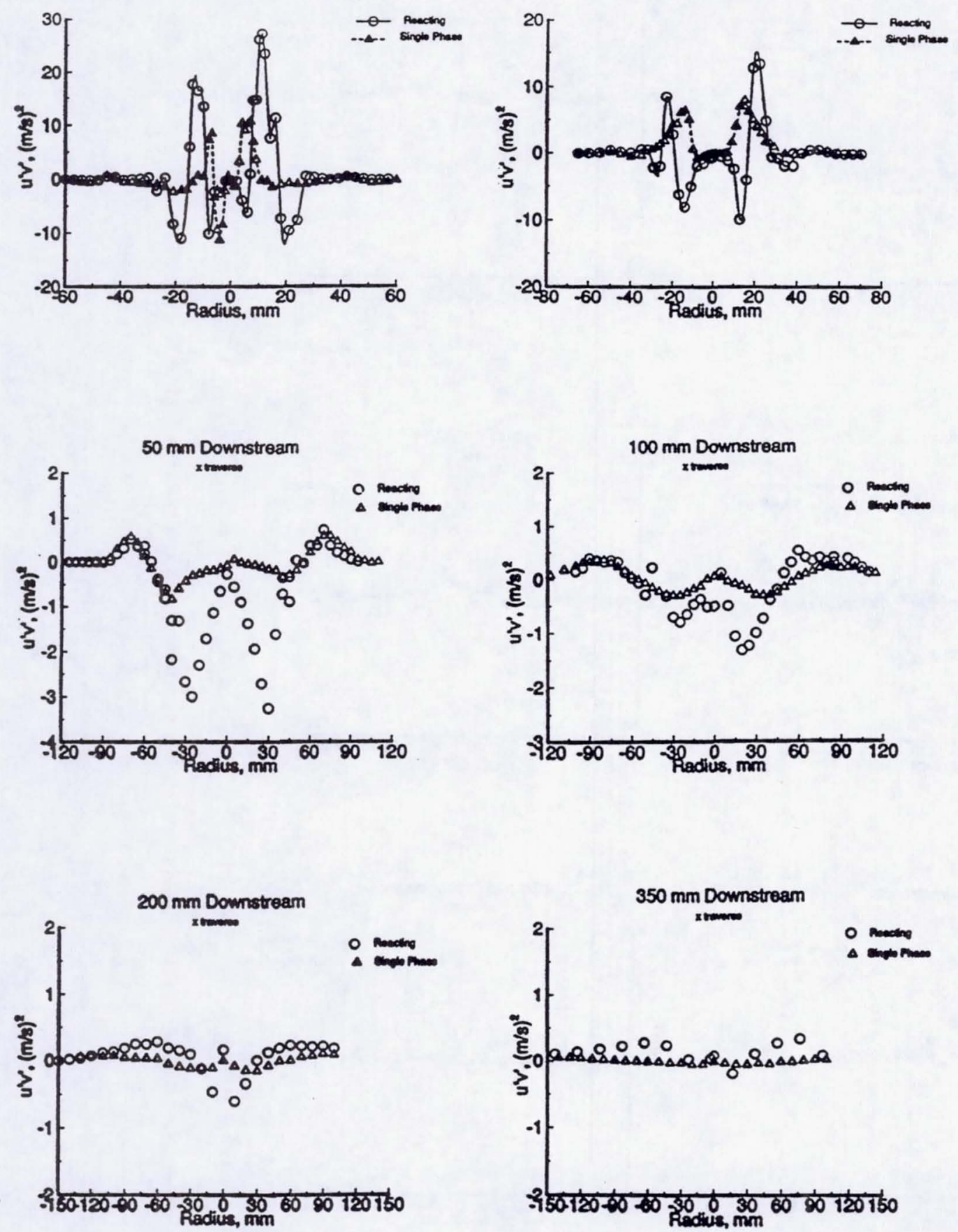

Figure 9.- Gas phase shear stress, u'v', profiles. 

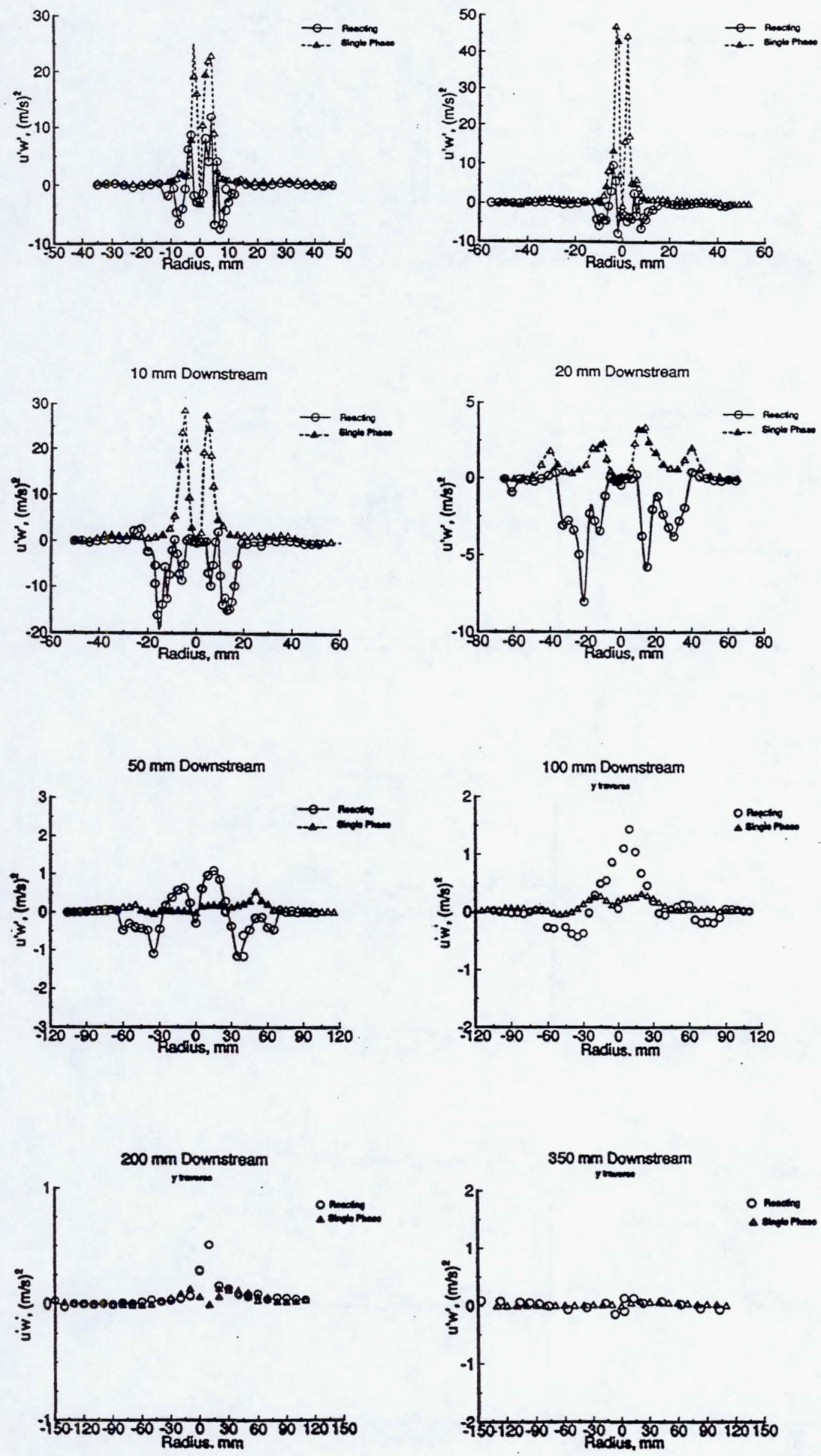

Figure 10.- Gas phase shear stress, u'w', profiles. 

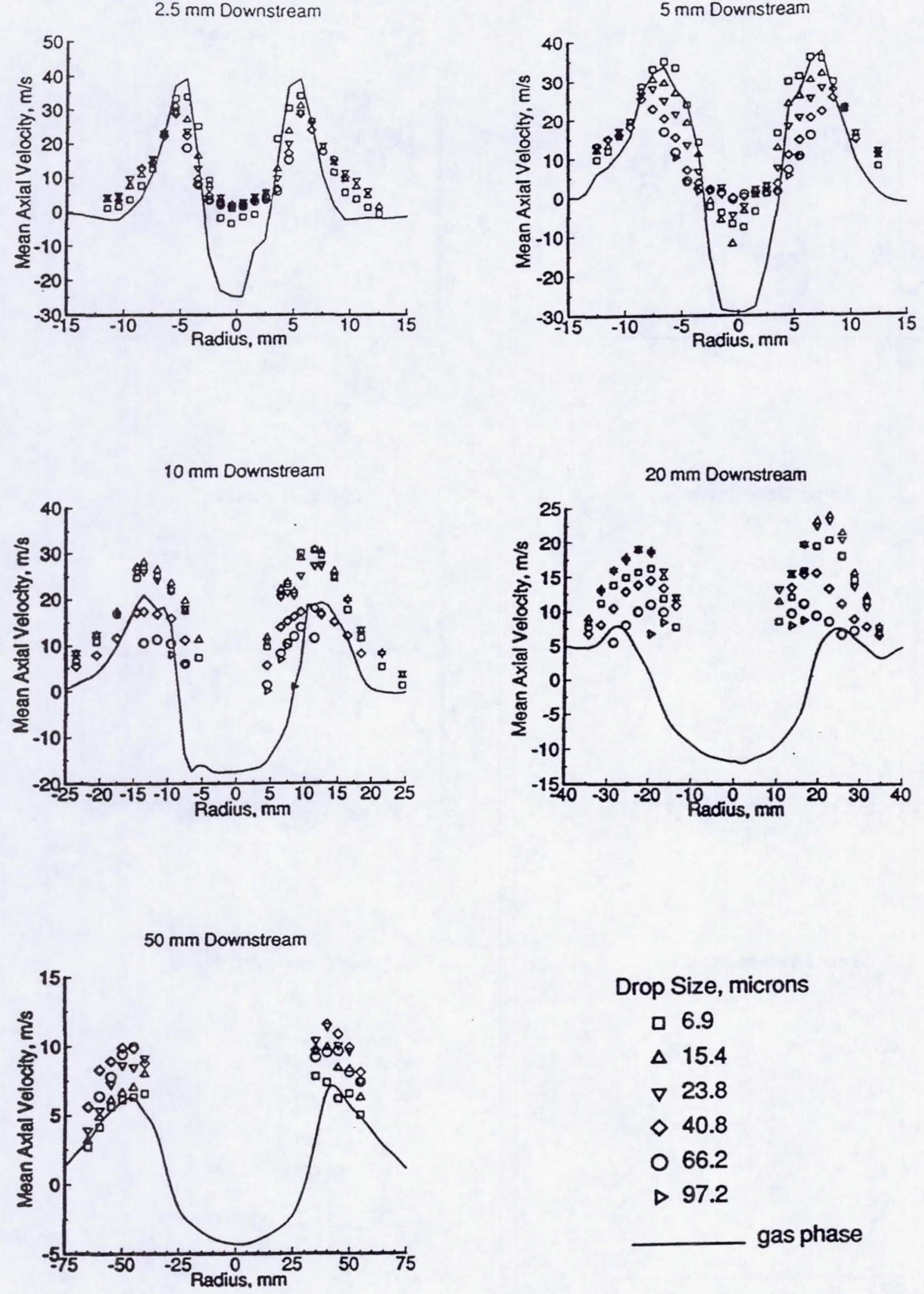
Drop Size, microns
6.9
$\triangle 15.4$
$\nabla 23.8$
$\diamond 40.8$
$\circ 66.2$
$\triangleright 97.2$ gas phase

Figure 11.- Drop mean axial velocity profiles. 

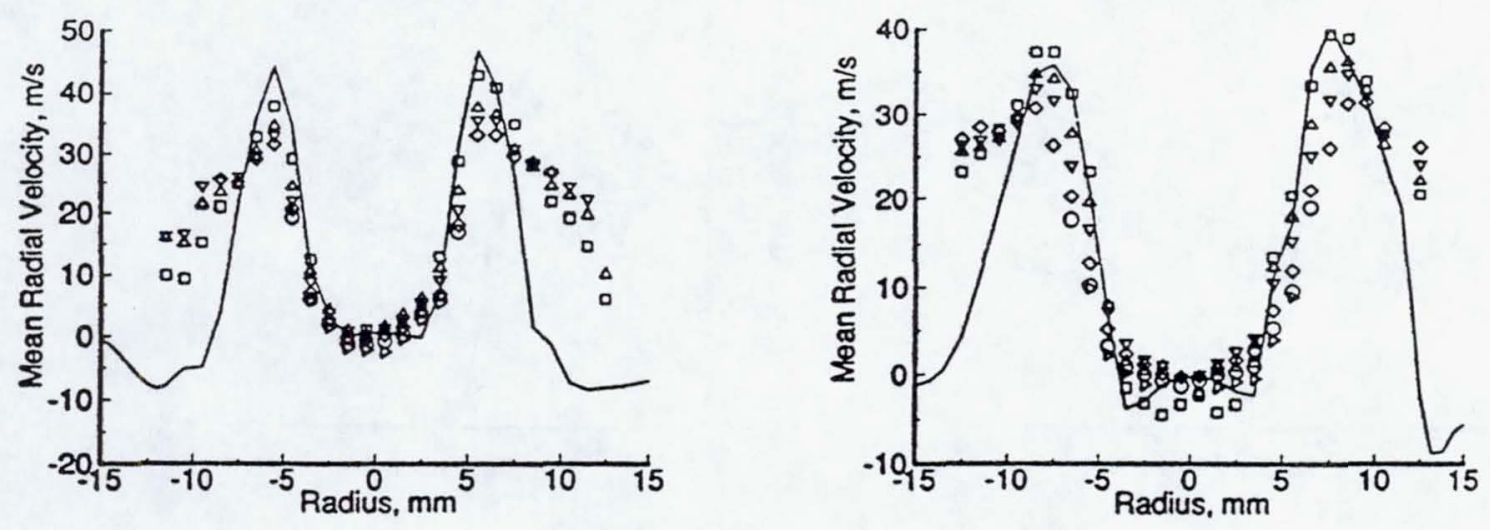

$10 \mathrm{~mm}$ Downstream

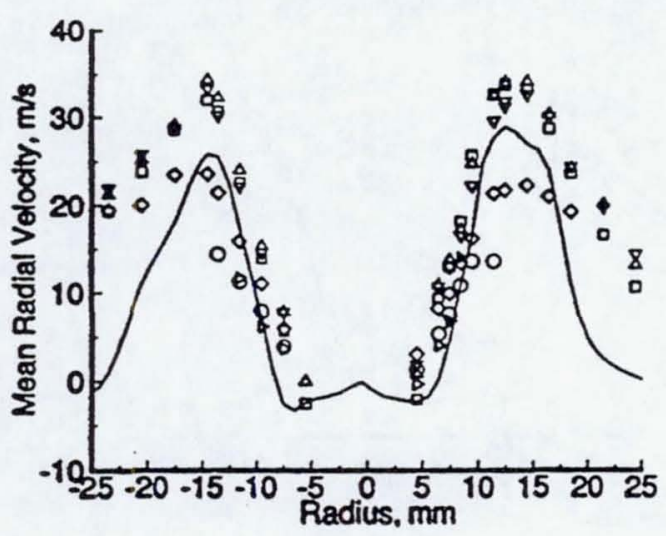

$20 \mathrm{~mm}$ Downstream

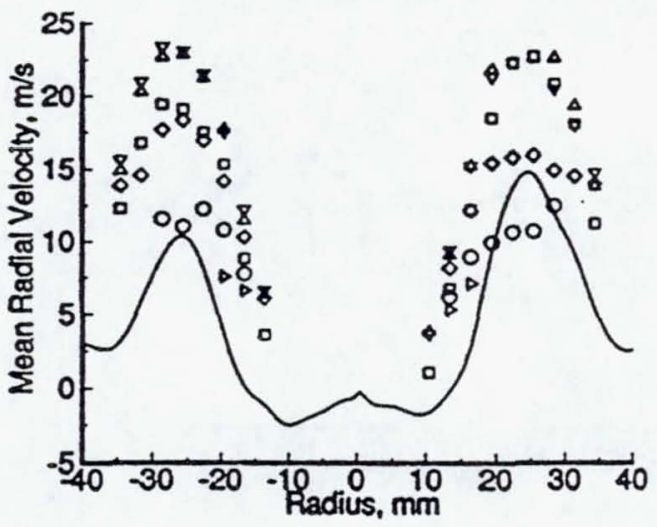

$50 \mathrm{~mm}$ Downstream

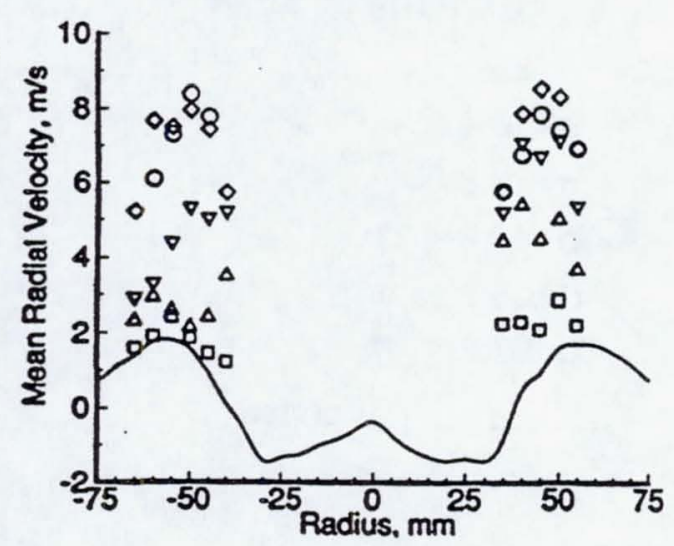

Drop Size, microns

6.9

$\triangle 15.4$

$\nabla 23.8$

$\diamond 40.8$

○ 66.2

$\triangleright 97.2$ gas phase

Figure 12.- Drop mean radial velocity profiles. 

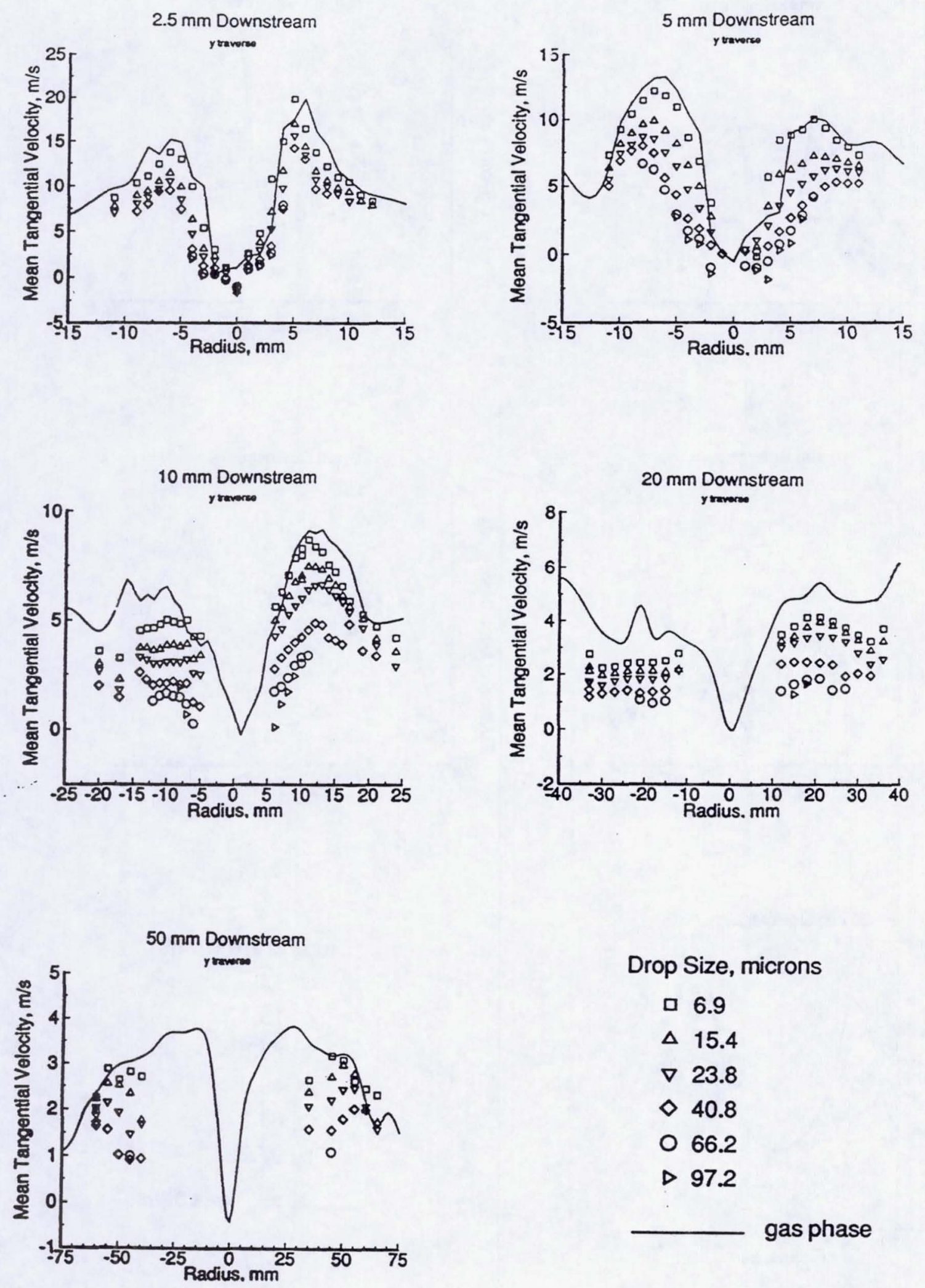

Figure 13.- Drop mean tangential velocity profiles. 

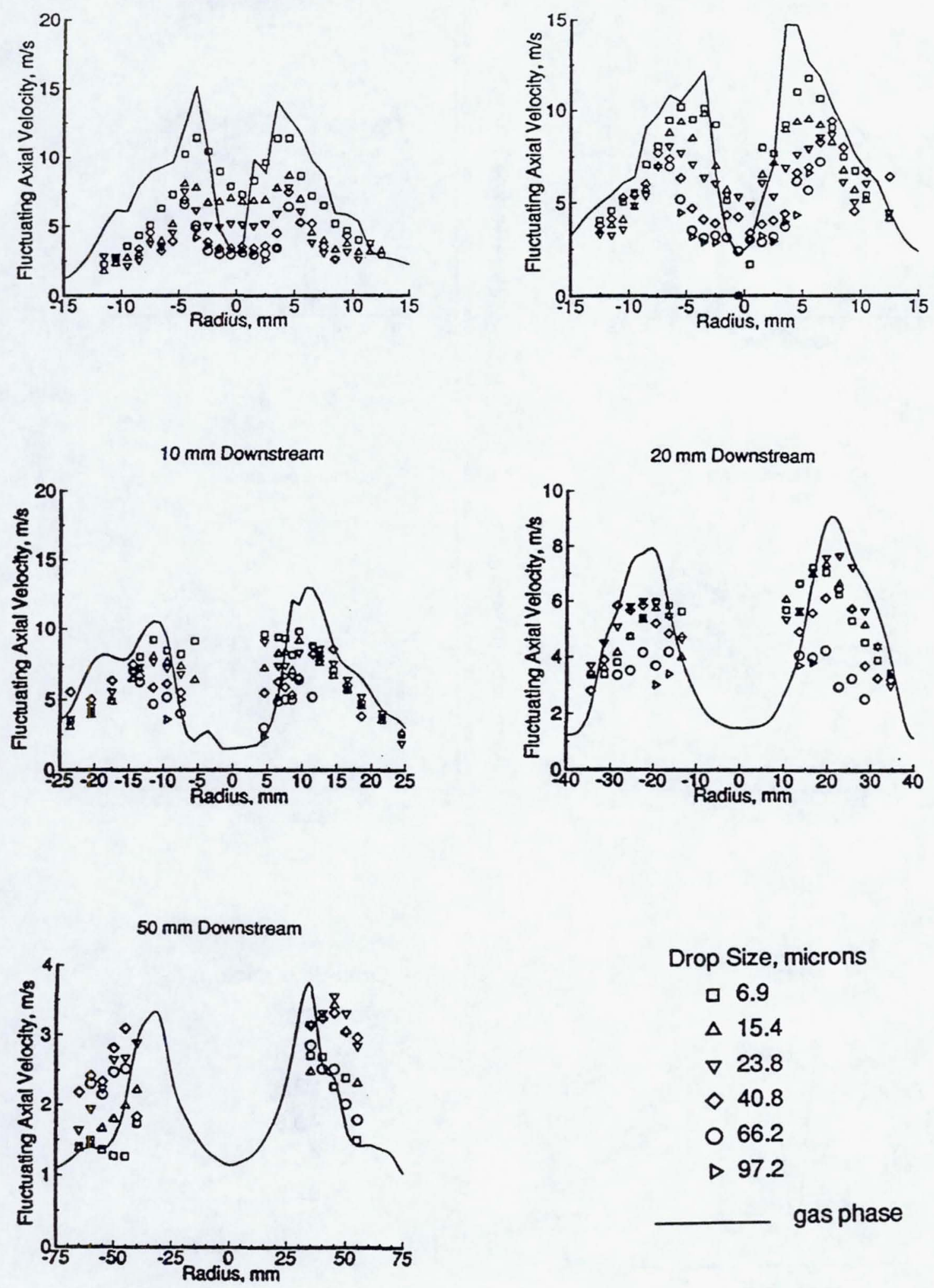

$$
\begin{aligned}
& \text { Drop Size, microns } \\
& \text { ㅁ } 6.9 \\
& \triangle 15.4 \\
& \nabla 23.8 \\
& \diamond 40.8 \\
& \text { ○ } 66.2 \\
& \text { D } 97.2
\end{aligned}
$$

Figure 14.- Fluctuating drop axial velocity profiles. 

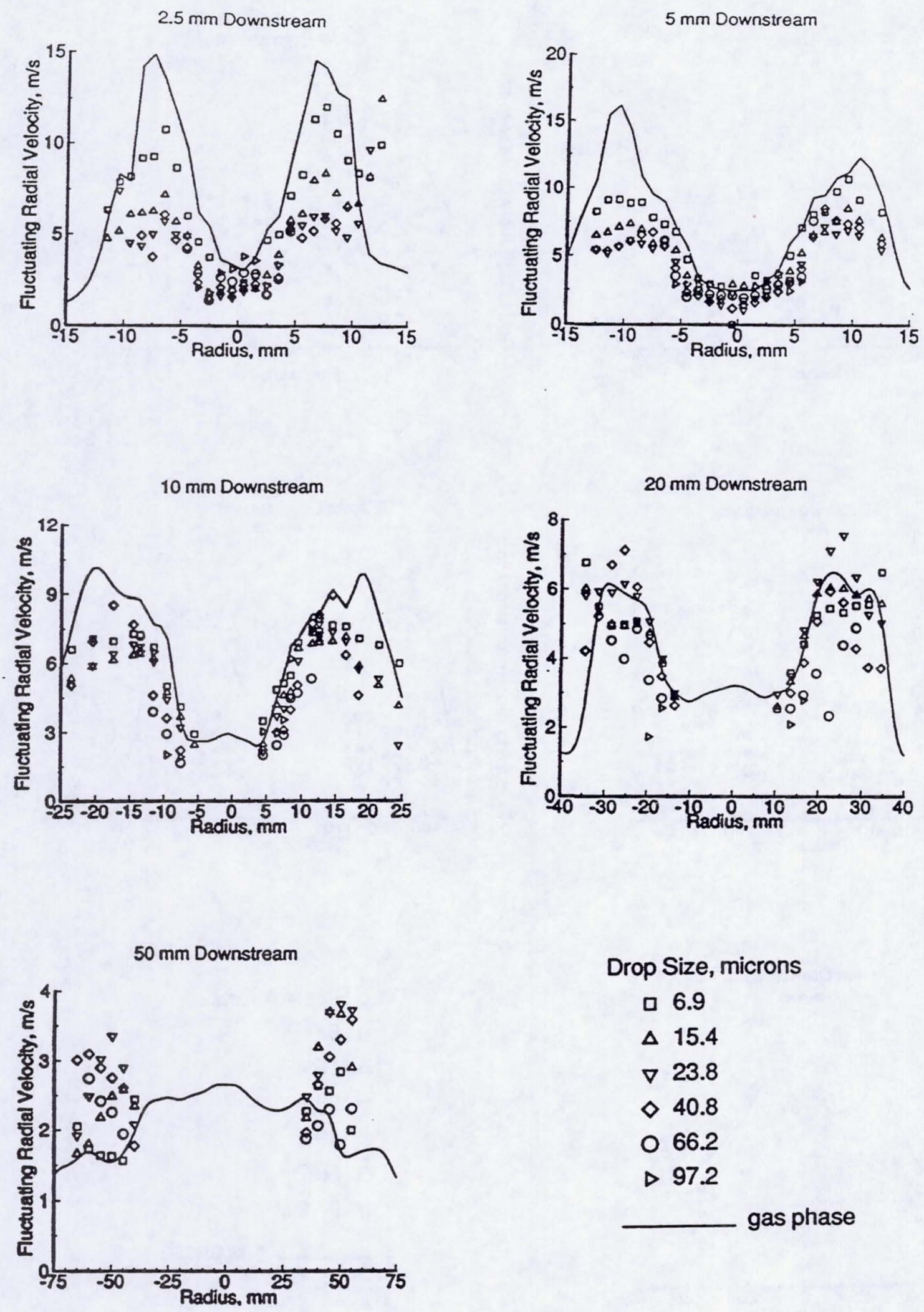

Drop Size, microns

口 6.9

$\triangle 15.4$

$\nabla 23.8$

$\diamond 40.8$

○ 66.2

$\triangleright 97.2$ gas phase

Figure 15.- Fluctuating drop radial velocity profiles. 

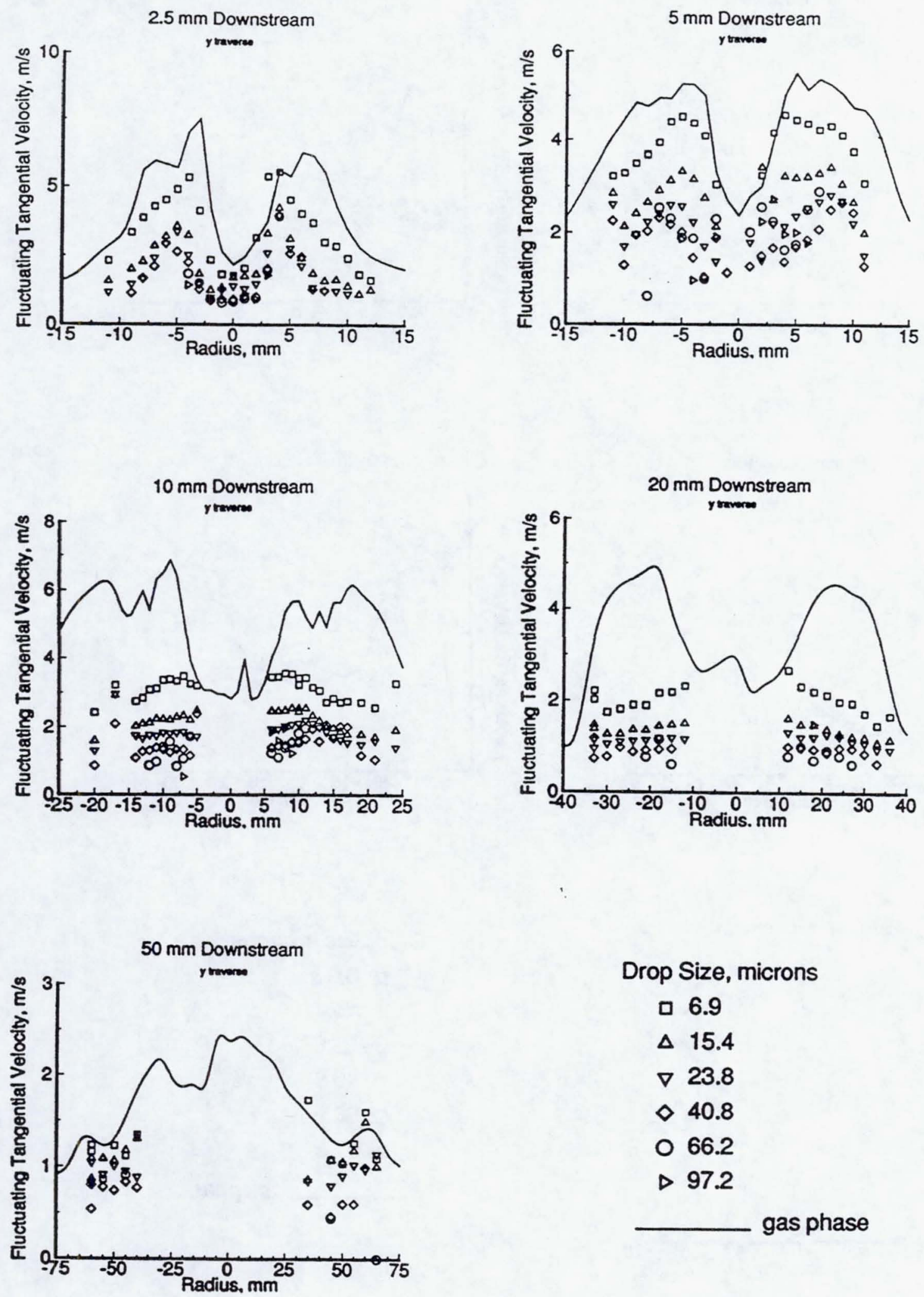

Drop Size, microns

6.9

$\triangle 15.4$

$\nabla 23.8$

$\diamond 40.8$

○ 66.2

$\triangleright 97.2$

gas phase

Figure 16.- Fluctuating drop tangential velocity profiles. 

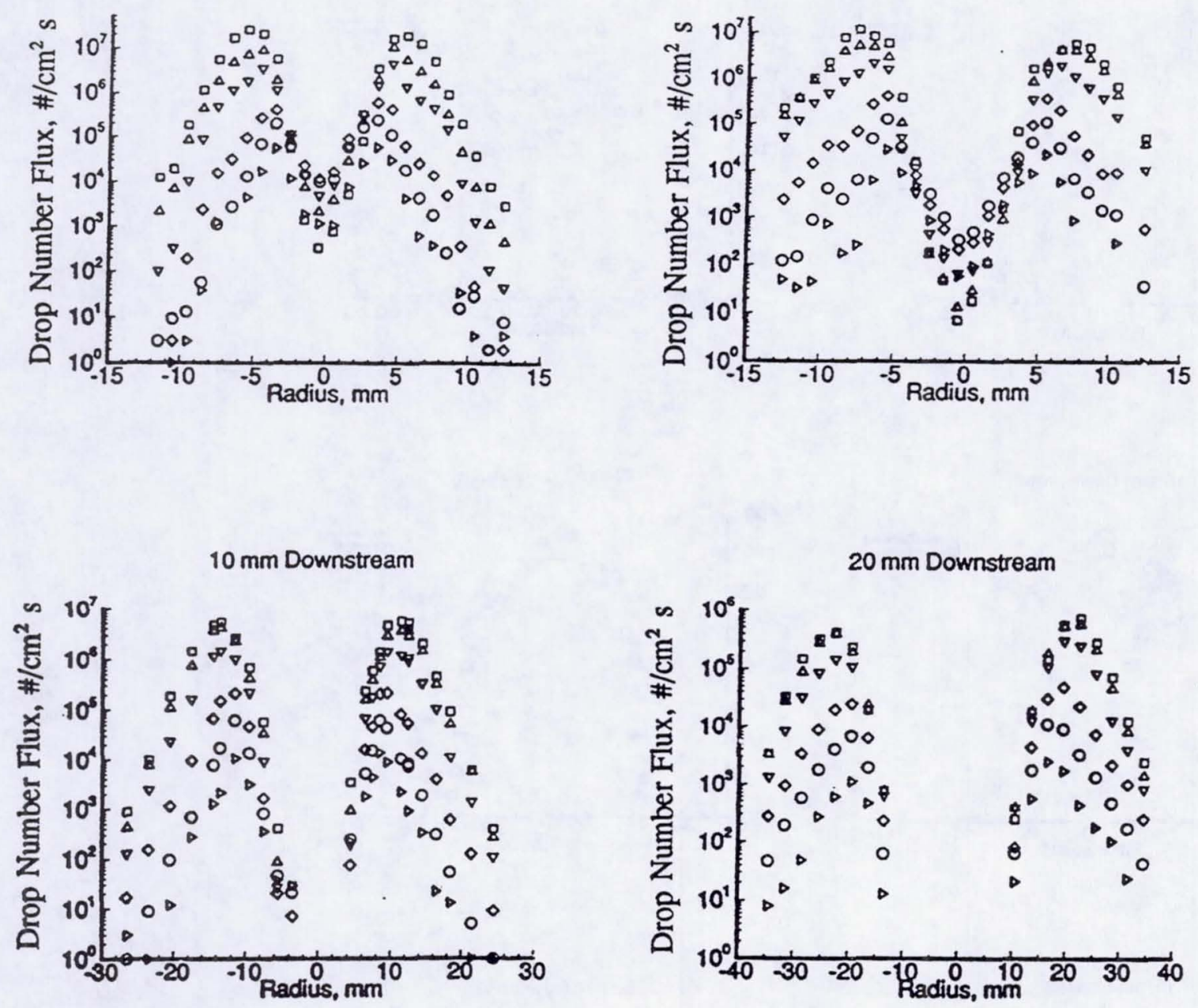

$50 \mathrm{~mm}$ Downstream

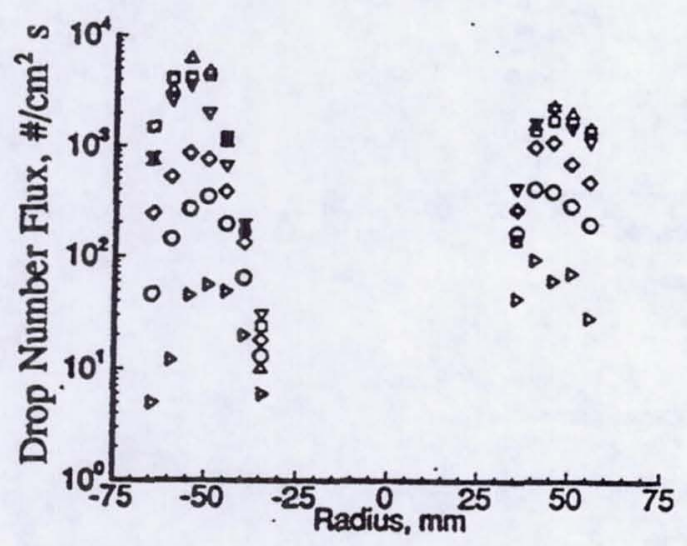

Drop Size, microns

ㅁ 6.9

$\triangle 15.4$

$\nabla 23.8$

$\diamond 40.8$

○ 66.2

D 97.2

Figure 17.- Drop number-flux profiles. 

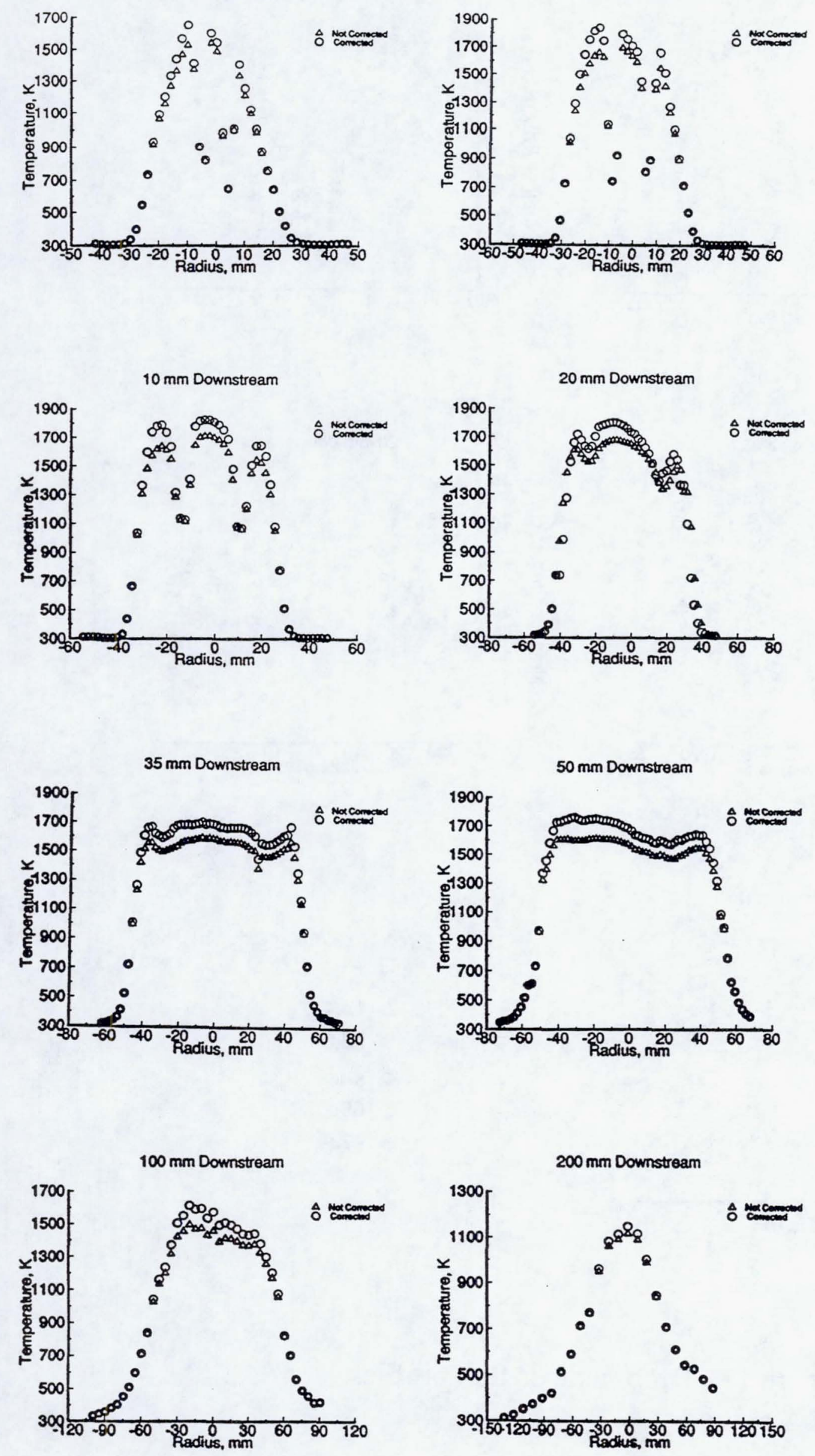

Figure 18.- Gas phase temperature profiles. 


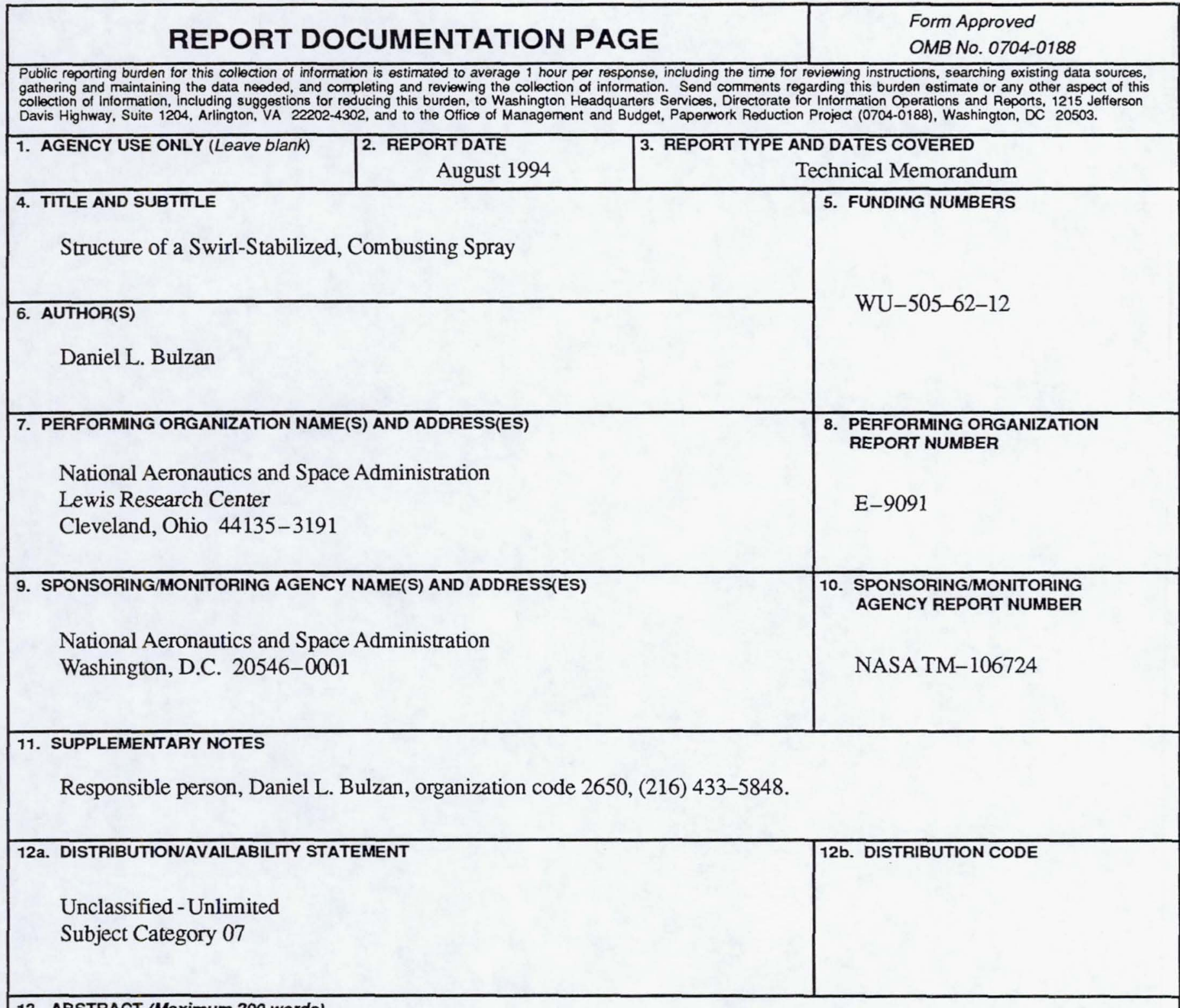

\section{ABSTRACT (Maximum 200 words)}

Measurements of the structure of a swirl-stabilized, reacting spray are presented. The configuration consisted of a research air-assist atomizer located in the center surrounded by a coflowing air stream. Both the air assist and coflow streams had swirl imparted to them in the same direction with 45 degree angle swirlers. The fuel and air entered the combustor at ambient temperature and the combustor was operated in an unconfined environment. The gas phase was seeded with aluminum oxide particles in order to obtain velocity measurements. Velocity measurements for the gas phase are reported for both an isothermal, single-phase case without drops and a reacting spray case at axial distances from 2.5 to $350 \mathrm{~mm}$ downstream of the nozzle. Both mean and fluctuating values are reported. Heptane fuel was used for all the experiments. Drop size and velocity, and drop number flux are also reported for five axial distances downstream. Both mean and fluctuating values are reported for the drops. The measurements were performed using a two-component phase/Doppler particle analyzer. Profiles across the entire flowfield where velocities were significant are presented. Mean gas phase temperatures were also measured intrusively using a single $\mathrm{pt} / \mathrm{pt}-13 \% \mathrm{rh}$ thermocouple and are reported at axial distances from 2.5 to $200 \mathrm{~mm}$ downstream of the nozzle.

\begin{tabular}{|c|c|}
\hline $\begin{array}{c}\text { 14. SUBJECT TERMS } \\
\text { Spray combustion; Swirl }\end{array}$ \\
\hline $\begin{array}{c}\text { 17. SECURTY CLASSIFICATION } \\
\text { OF REPORT } \\
\text { Unclassified }\end{array}$ & $\begin{array}{c}\text { 18. SECURTY CLASSIFICATION } \\
\text { OF THIS PAGE } \\
\text { Unclassified }\end{array}$ \\
\hline
\end{tabular}

NSN 7540-01-280-5500

\begin{tabular}{|c|c|}
\hline & $\begin{array}{c}\text { 15. NUMBER OF PAGES } \\
32\end{array}$ \\
\hline & $\begin{array}{r}\text { 16. PRICE CODE } \\
\mathrm{A} 03\end{array}$ \\
\hline $\begin{array}{l}\text { 19. SECURITY CLASSIFICATION } \\
\text { OF ABSTRACT } \\
\text { Unclassified }\end{array}$ & 20. LIMITATION OF ABSTRACT \\
\hline
\end{tabular}

Standard Form 298 (Rev. 2-89) Prescribed by ANSI Std. Z39-18 298-102 